\title{
Representation of the tropical stratospheric zonal wind in global atmospheric reanalyses
}

\author{
Yoshio Kawatani $^{1}$, Kevin Hamilton ${ }^{2}$, Kazuyuki Miyazaki ${ }^{1}$, Masatomo Fujiwara ${ }^{3}$, and James A. Anstey ${ }^{4}$ \\ ${ }^{1}$ Japan Agency for Marine-Earth Science and Technology, Yokohama, 236-0001, Japan \\ ${ }^{2}$ International Pacific Research Center, University of Hawaii, Honolulu, 96822, USA \\ ${ }^{3}$ Faculty of Environmental Earth Science, Hokkaido University, Sapporo, 060-0810, Japan \\ ${ }^{4}$ Canadian Centre for Climate Modelling and Analysis, University of Victoria, Victoria, V8W 2Y2, Canada \\ Correspondence to: Yoshio Kawatani (yoskawatani@jamstec.go.jp)
}

Received: 27 January 2016 - Published in Atmos. Chem. Phys. Discuss.: 1 February 2016

Revised: 10 May 2016 - Accepted: 19 May 2016 - Published: 2 June 2016

\begin{abstract}
This paper reports on a project to compare the representation of the monthly-mean zonal wind in the equatorial stratosphere among major global atmospheric reanalysis data sets. The degree of disagreement among the reanalyses is characterized by the standard deviation (SD) of the monthly-mean zonal wind and this depends on latitude, longitude, height, and the phase of the quasi-biennial oscillation (QBO). At each height the SD displays a prominent equatorial maximum, indicating the particularly challenging nature of the reanalysis problem in the low-latitude stratosphere. At $50-70 \mathrm{hPa}$ the geographical distributions of $\mathrm{SD}$ are closely related to the density of radiosonde observations. The largest SD values are over the central Pacific, where few in situ observations are available. At $10-20 \mathrm{hPa}$ the spread among the reanalyses and differences with in situ observations both depend significantly on the QBO phase. Notably the easterly-to-westerly phase transitions in all the reanalyses except MERRA are delayed relative to those directly observed in Singapore. In addition, the timing of the easterlyto-westerly phase transitions displays considerable variability among the different reanalyses and this spread is much larger than for the timing of the westerly-to-easterly phase changes. The eddy component in the monthly-mean zonal wind near the Equator is dominated by zonal wavenumber 1 and 2 quasi-stationary planetary waves propagating from midlatitudes in the westerly phase of the QBO. There generally is considerable disagreement among the reanalyses in the details of the quasi-stationary waves near the Equator. At each level, there is a tendency for the agreement to be best near the longitude of Singapore, suggesting that the Singa-
\end{abstract}

pore observations act as a strong constraint on all the reanalyses. Our measures of the quality of the reanalysis clearly show systematic improvement over the period considered (1979-2012). The SD among the reanalysis declines significantly over the record, although the geographical pattern of SD remains nearly constant.

\section{Introduction}

The dynamics governing the circulation in the tropical stratosphere have attracted much interest over the years (e.g., Wallace, 1973; Baldwin et al., 2001). As in other regions of the middle atmosphere, the day-to-day and higher-frequency variations of the flow in the tropical stratosphere are believed to be dominated by a spectrum of vertically propagating waves excited in the troposphere. What makes the low-latitude stratosphere so remarkable is that the forcing of the zonal-mean flow by these waves leads to the very large-amplitude, low-frequency quasi-periodic cycle known as the quasi-biennial oscillation (QBO). In the tropical stratosphere, the QBO clearly dominates other aspects of interannual variability and even swamps the annual and semiannual variations in the zonal-mean circulation, at least up to $\sim 3 \mathrm{hPa}$. Although rooted in the tropics, the QBO has global impacts. The QBO strongly influences interannual variations in circulation and composition throughout the stratosphere. The QBO also affects the circulation at the Earth's surface and is an important consideration in extended-range weather forecasts (e.g., Baldwin et al., 2001). Recently, Yoo and 
Son (2016) indicate the QBO exerts greater influence on the Madden-Julian Oscillation than does the El Niño-Southern Oscillation.

The state of the QBO up to the middle stratosphere can be characterized by the time series of monthly-mean, nearequatorial zonal winds at levels between 10 and $70 \mathrm{hPa}$ maintained by the Free University of Berlin (FUB; e.g., Naujokat, 1986) since 1953. The monthly values in the FUB series are based on operational balloon soundings, and the FUB record has been stitched together from such observations at Canton Island $\left(2.8^{\circ} \mathrm{S}, 172^{\circ} \mathrm{W}\right.$ from January 1953 to August 1967$)$, Gan $\left(0.7^{\circ} \mathrm{S}, 73^{\circ} \mathrm{E}\right.$ from September 1967 to December 1975), and Singapore $\left(1.4^{\circ} \mathrm{N}, 104^{\circ} \mathrm{E}\right.$ since 1976$)$. The high quality of these balloon data, and the close proximity of the stations to the Equator, has led FUB series to be widely used, despite being based on only a single station each month (and despite modest inhomogeneities that the changes of station location may introduce into the record; see Sect. 3 below).

Global atmospheric analyses that assimilate all available satellite remote sensing and in situ observations are another potential source of information about the QBO and other aspects of the circulation in the tropical stratosphere. Data assimilation is the technique for combining different observational data sets with a model, by considering the characteristics of each measurement and taking into account errors in both the measurements and the model (e.g., Kalnay, 2003). Advanced data assimilation schemes like the 4DVar technique use the information provided by various measurements, such as radiosonde and satellite-derived measurements, and propagates it, in time and space, from a limited number of observable variables to a wide range of meteorological variables to provide global fields that are dynamically consistent and in agreement with the observations. Meteorological reanalyses have been conducted at operational centers using various approaches, which ingest a variety of observations over the period of each reanalysis product. Differences in the forecast model, assimilated measurements, and data assimilation technique used for producing reanalysis data sets can lead to differences in their representation of the mean state, variability, and long-term trend of atmospheric fields.

A number of factors combine to make the global meteorological analysis process particularly challenging in the tropical middle atmosphere.

i. One challenge is the relative paucity of in situ data, even when attention is restricted to levels at and below $10 \mathrm{hPa}$ (i.e., the usual upper bound for most operational balloon soundings). There are large ocean areas in the tropics with no balloon observations. Even over land areas, the observations in the stratosphere at many stations are sparse. At stratospheric levels, the zonal wind measurements at many stations near the Equator tend to have short overall records or records with many months that have no observations (or not enough to compute a stable monthly mean). This leads to gaps in time series of monthly-mean winds (e.g., Hamilton, 1984; Kawatani and Hamilton, 2013).

ii. Near the Equator the Coriolis parameter is small, so observations of the temperature from satellite remote sensing do not constrain the wind field as strongly as at higher latitudes. Even when we assume the nearequatorial flow really is close to thermal wind balance (Reed, 1962; Randel et al., 1999), the computed geostrophic wind shears are extremely sensitive to small errors in the observed temperatures.

iii. The flow in the tropical stratosphere exhibits variations on very small vertical scales. This limits the usefulness of the relatively coarse-resolution satellite remotesensing temperature retrievals. Even the monthly-mean zonal wind in this region displays thin layers where the wind can change by $\sim 30 \mathrm{~m} \mathrm{~s}^{-1}$ over $\sim 3 \mathrm{~km}$. Satellite radiances used in global assimilations have an effective vertical resolution of several kilometers (e.g., Huesmann and Hitchman, 2003). Huesmann and Hitchman (2003) note that in such shear regions the assimilation scheme will have to reconcile the strong wind shears measured directly by balloons with the somewhat weaker thermal winds consistent with the satellitederived temperature gradients (artificially damped due to the coarse vertical resolution).

iv. Modern data assimilation approaches use general circulation model (GCM) simulations to obtain background (i.e., first guess) information and to determine data assimilation analysis increments. The tropical stratosphere is perhaps the only region of the atmosphere where most free-running GCMs have simulations with zero-order errors in the zonal-mean circulation (i.e., nothing even resembling a realistic QBO). This is because most GCMs display fairly steady, weak prevailing zonal winds due to failure to reproduce a spontaneous QBO. Such models typically relax any QBO-like zonal winds in the initial condition towards the model climatology (e.g., Hamilton and Yuan, 1992; Saha et al., 2006; Boer and Hamilton, 2008) and so the persistent model bias could act against the data assimilation analysis increments and damp the QBO signals as introduced by data assimilation in the reanalysis fields. It should be noted that the situation is now slowly changing and several models have simulated a fairly realistic spontaneous the QBO in the equatorial stratosphere. Such models typically either employ fine vertical resolution as well as representation of momentum transports from smallscale non-stationary gravity waves either through high horizontal resolution (Kawatani et al., 2010, and reference therein) or by parameterization (Orr et al., 2010; Kawatani and Hamilton, 2013; Anstey et al., 2016).

These special challenges in data assimilation for the tropical stratosphere have led to problems in actual global assimila- 
tion products, although there have been clear improvements over the last 2 decades in the ability of analysis systems to represent this region of the atmosphere. Trenberth (1992) documents a total misrepresentation of the QBO in the tropical stratosphere of ECMWF operational global analyses in the early 1980 s, but finds that the situation improved considerably after changes in the assimilation scheme were introduced in May 1986.

In the 1990s some major meteorological centers started producing retrospective reanalysis products that employed multivariate statistical data assimilation methods such as optimal interpolation and a three-dimensional variational (3DVAR) scheme to combine all available data over some extended period. Such reanalyses have obvious advantages for research applications requiring the most homogeneous possible data set throughout an extended period. Two of the early major products were the ECMWF "ERA-15" reanalysis (covering 1979 to 1994) and the first NCAR/NCEP reanalysis (covering 1948-near present). The QBO in the tropical stratosphere in these products was examined by Pawson and Fiorino $(1998,1999)$ and Huesmann and Hitchman (2001, 2003), who found that the reanalyses displayed equatorial QBO variations that were clearly smaller in amplitude than in the real atmosphere. Randel et al. (2004) indicated that QBO variations in temperature and zonal wind were underestimated in most reanalyses available at that time, as compared to Singapore radiosonde data. They found that only ERA-40 had realistic zonal wind amplitudes above $30 \mathrm{hPa}$.

Some centers have now produced multiple reanalyses covering the same (or overlapping) periods; these more recent products are derived with updated data assimilation systems. Notable among these are the ECMWF ERA-40 (September 1958 to August 2002) and ERA-Interim (1979 to present). These products have improved representation of the QBO amplitude over that in ERA-15 (e.g., Pascoe et al., 2005; Baldwin and Gray, 2005). Baldwin and Gray (2005) compared the FUB zonal wind with ERA-40 data and showed that the zonal mean equatorial ERA-40 wind is quite close to that indicated in the FUB data.

Additional major reanalysis data sets have become available recently. The present paper reports on one of the studies contributing to the SPARC Reanalysis Intercomparison Project (S-RIP; Fujiwara and Jackson, 2013; Errera et al., 2015), which is focused on evaluating reanalysis output for the stratosphere. We compare the representation of the circulation in the tropical stratosphere among several contemporary reanalysis products and validate the reanalyses against in situ observations. We have mostly limited our attention to just a single aspect of the circulation, namely the monthlymean zonal wind. We limit our consideration to low latitudes $\left(20^{\circ} \mathrm{N}-20^{\circ} \mathrm{S}\right)$ and a height range $(10-70 \mathrm{hPa})$ in which the QBO is strong and where substantial balloon data are available for comparison. We have also restricted our attention to the period starting in 1979 when NOAA operational satellite radiance observations became available and were incorpo- rated as an important data source in all the reanalyses. We appreciate that other aspects of the reanalyses in this region are also of interest, notably the ability of the reanalyses to represent accurately the large-scale transport circulation in the stratosphere (e.g., Coy and Swinbank, 1997; Abalos et al., 2015; Miyazaki et al., 2016), but these aspects will be left for future research.

Each reanalysis uses a different forecast model and assimilation scheme, and the types and numbers of assimilated observational data are also different among reanalyses. Furthermore, it is not feasible to determine exactly what observational data were actually assimilated at each data assimilation analysis step (e.g., what data quality control and bias correction procedures were actually applied). These complications make it somewhat difficult to attribute conclusively all the differences among the reanalyses products. However, we believe it is interesting to investigate representations of key phenomena in the reanalyses and we hope that such investigation will contribute to basic understanding and to improving future reanalysis products. We will show that, even with our somewhat narrow focus, some interesting conclusions concerning the representation of the tropical stratospheric circulation will emerge.

The outline of this paper is as follows. Section 2 briefly describes the reanalysis products that we evaluated and the station balloon data we employed. Section 3 investigates differences of the tropical zonal wind among reanalyses. Section 4 discusses evolution of the differences among reanalyses with time as different data sources become available. Section 5 summarizes the study and provides concluding remarks.

\section{Reanalysis and radiosonde observation data}

We analyzed monthly-mean zonal wind and temperature in nine sets of global reanalyses data (NCEP-1, Kalnay et al., 1996; NCEP-2, Kanamitsu et al., 2002; NCEP-CFSR, Saha et al., 2010; ERA-40, Uppala et al., 2005; ERA-I, Dee et al., 2011; JRA-25, Onogi et al., 2007; JRA-55, Kobayashi et al., 2015; MERRA, Rienecker et al., 2011, and MERRA2, Molod et al., 2015). Monthly-mean data for $20^{\circ} \mathrm{S}-20^{\circ} \mathrm{N}$ and $10-70 \mathrm{hPa}$ after 1979 are mainly analyzed except for MERRA-2, which has data only after January 1980. Data before December 2012 are investigated, except for ERA-40 and NCEP-CFSR, which are available until August 2002 and December 2010, respectively. With the exception of MERRA-2, none of the global dynamical models used in the assimilations would simulate the QBO when in free running mode. The dynamical model used in producing the MERRA-2 reanalyses is able to simulate a spontaneous QBO in the tropical stratosphere because it includes quite strong parameterized momentum fluxes from non-orographic gravity waves (Fig. 3 of Molod et al., 2015).

One key observational data set we employed for comparisons is the near-equatorial monthly-mean values of oper- 


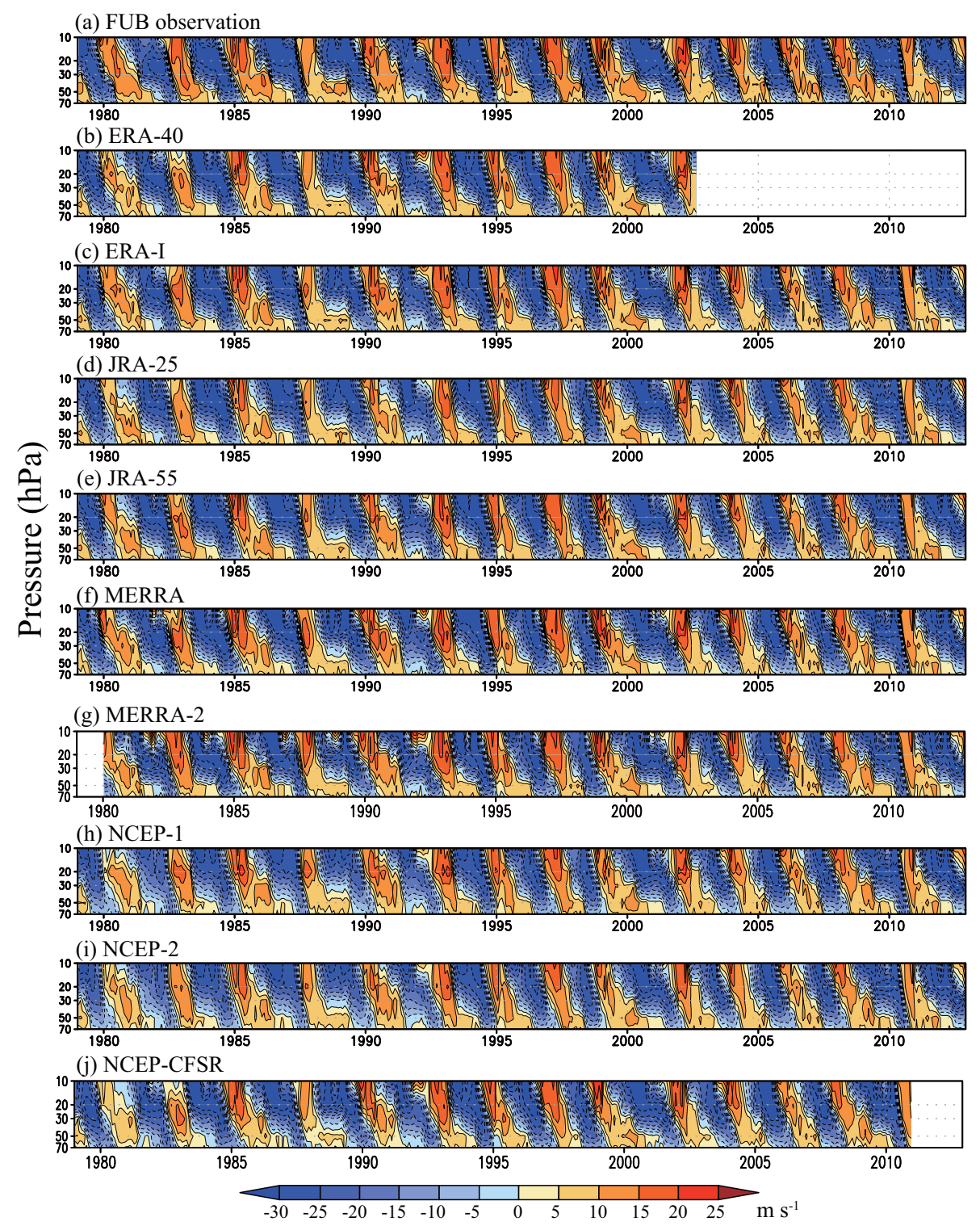

Figure 1. Time-height cross section of the FUB zonal wind and each reanalysis zonal wind over Singapore (104 ${ }^{\circ}$, $\left.1.4^{\circ} \mathrm{N}\right)$ from 1979 to 2012. The color intervals are $5 \mathrm{~m} \mathrm{~s}^{-1}$.

ational balloon-borne radiosonde observations compiled by FUB (Freie Universität Berlin, 2016; Naujokat, 1986). The FUB data during 1979-2012 (i.e., period analyzed in this study) are based on Singapore observations.

We have also used monthly-mean values of the zonal wind at many other radiosonde stations provided in the Integrated Global Radiosonde Archive (NOAA, 2016; Durre et al., 2006). For $10^{\circ} \mathrm{S}-10^{\circ} \mathrm{N}$ IGRA includes balloon data from $\sim 220$ stations. When twice daily observations are available, the IGRA provides monthly means of observations at 00:00 and at 12:00 UTC separately. As in Kawatani and Hamilton (2013), where possible, the monthly values for 00:00 and 12:00 UTC are averaged, but the single values are used when only 00:00 or only 12:00 UTC data are available. The diur- nal cycle of the wind in the lower stratosphere is expected to be small, and indeed we have found that generally the monthly-mean zonal wind data measured at 00:00 UTC are nearly identical to that at 12:00 UTC.

In order to compare the data among reanalyses which have different spatial resolutions, all reanalysis variables are interpolated linearly to the ERA-I grid (i.e., $1.5^{\circ}$ resolution in longitude and latitude, 37 vertical levels from 1000 to $1 \mathrm{hPa}$ ). When reanalysis data are compared with FUB/IGRA observational data, the reanalysis values are interpolated to the station locations. 


\section{Differences of the tropical zonal wind among reanalyses}

\subsection{Dependence of differences on longitude and height}

Figure 1 shows the FUB zonal wind and the zonal wind in each reanalysis included in this study in Singapore $\left(104^{\circ} \mathrm{E}\right.$, $1.4^{\circ} \mathrm{N}$ ) from 1979 to 2012 . All the reanalyses have a reasonably close resemblance to the FUB observations. Notably each reanalysis clearly captures the basic features of the QBO seen in the FUB data, including the cycle-to-cycle variation in period and amplitude.

Figure 2 displays time variations of the zonal wind in each reanalysis at 10, 20, 30, 50, and $70 \mathrm{hPa}$ over Singapore compared with the FUB observations. Also shown are the root mean square (RMS) differences between FUB and each reanalysis zonal wind averaged from 10 to $70 \mathrm{hPa}$. Reanalysis zonal winds are generally close to the FUB zonal wind. The RMS differences display somewhat noisy variations but an overall trend to smaller values over time is apparent. The zonal winds in NCEP-1 and NCEP-2 are generally underestimated, especially in the 1980 s over $20-50 \mathrm{hPa}$. The most obvious anomaly in the reanalysis winds at $10 \mathrm{hPa}$ is found in MERRA-2, which exhibits spurious semiannual variations in the 1980s and in late 1993 particularly during easterly phase of the QBO (Figs. 1g and 2a). The downward propagation of westerly semiannual oscillation (SAO) phases is enhanced during these periods, which could be caused by overly strong gravity wave forcing (Fig. 3 of Molod et al., 2015). Coy et al. (2016) note that MERRA-2 appears to overemphasize the annual cycle before 1995 .

The RMS differences from FUB values are smallest in ERA-I, while those in NCEP-1 and NCEP-2 are much larger than those in the other reanalyses. MERRA-2 represents large RMS differences in 1980s (Fig. 2f), mainly due to the enhanced SAO at $10 \mathrm{hPa}$. The NCEP-CFSR actually uses the ERA-40 stratospheric wind profiles as bogus observations in the tropics from 1 July 1981 to 31 December 1998 to obtain a reasonable QBO (Saha et al., 2010). We confirmed the differences between NCEP-CFSR and ERA-40 during this period are nearly 0 . For these reasons, our study focuses mainly on the five reanalyses: ERA-40, ERA-I, JRA-25, JRA-55, and MERRA. But note that the MERRA-2 zonal winds show improved representation of the QBO compared to MERRA at 30-50 hPa (Coy et al., 2016).

In order to quantify the spread among reanalyses, the standard deviations (SDs) among the reanalyses are calculated as follows:

$\mathrm{SD}=\sqrt{\sum_{i}^{N}\left(u_{i}-[u]\right)^{2} / N}$

where $i$ labels the individual data sets and there are $N$ data sets included. The square brackets denote the mean over all $N$ reanalyses. The SD is calculated for each month using
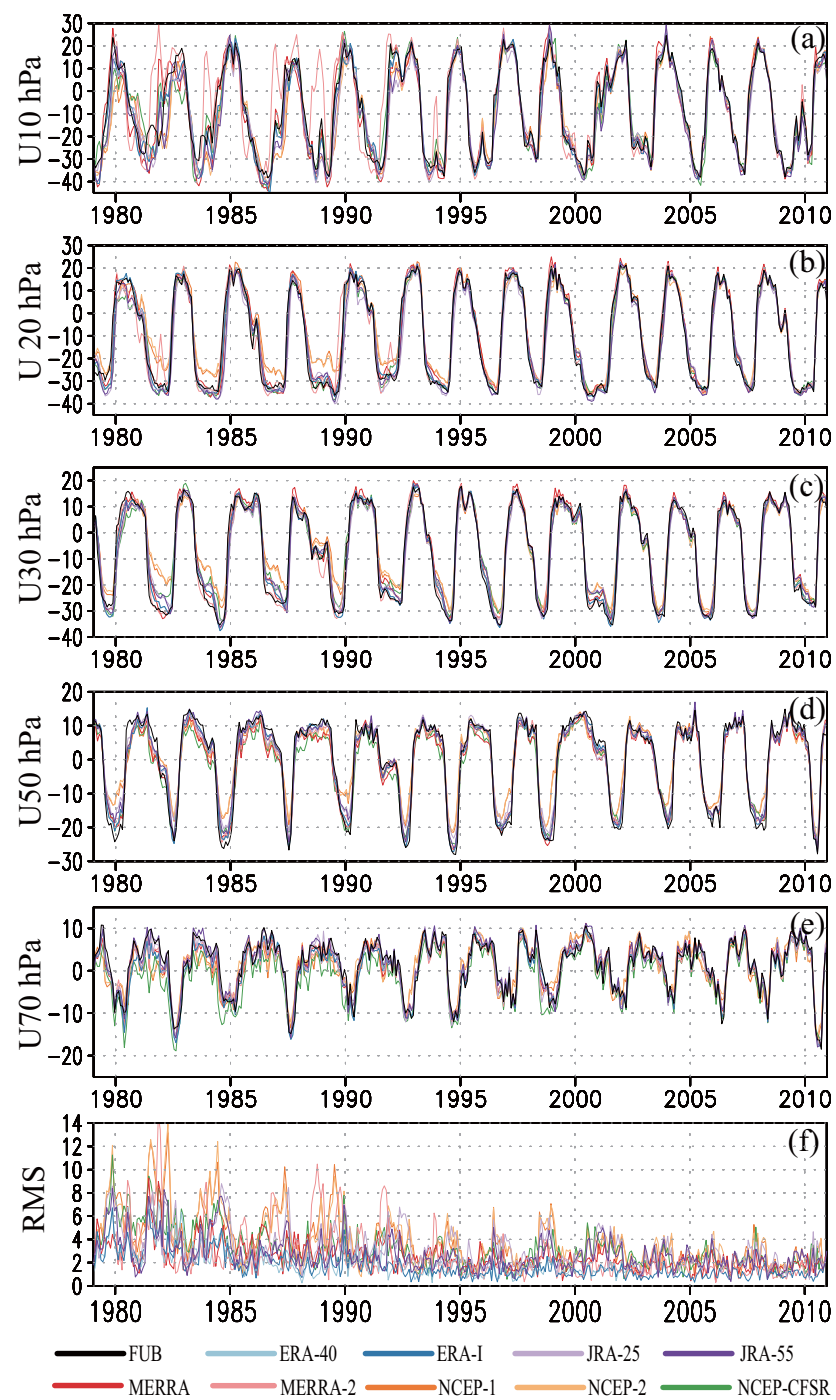

Figure 2. Time variations of the zonal wind over Singapore at (a) 10, (b) 20, (c) 30, (d) 50, and (e) $70 \mathrm{hPa}$ for FUB observation (black), ERA-40 (light blue), ERA-I (blue), JRA-25 (light purple), JRA-55 (purple), MERRA (red), MERRA-2 (pink), NCEP1 (orange), NCEP-2 (yellow), and NCEP-CFSR (green); (f) Root mean square differences between the FUB and each reanalysis zonal wind, averaged at $70-10 \mathrm{hPa}$.

monthly-mean zonal wind. Because the ERA-40 data are only provided until August 2002, attention will sometimes be restricted to the SD during January 1979 to December 2001.

The latitude-height distributions of the zonal mean and time mean of the SD among five reanalyses (1979-2001) are displayed in Fig. 3a. Large SD is seen in the upper troposphere and the stratosphere at low latitudes, while the SD in the extratropical regions is much smaller. Figure $3 \mathrm{~b}$ and $\mathrm{c}$ depict the SD among four reanalyses (ERA-I, JRA-25, JRA-55, and MERRA) and among the three latest reanalyses (ERA-I, JRA-55, and MERRA) in 1979-2012. These are discussed in 


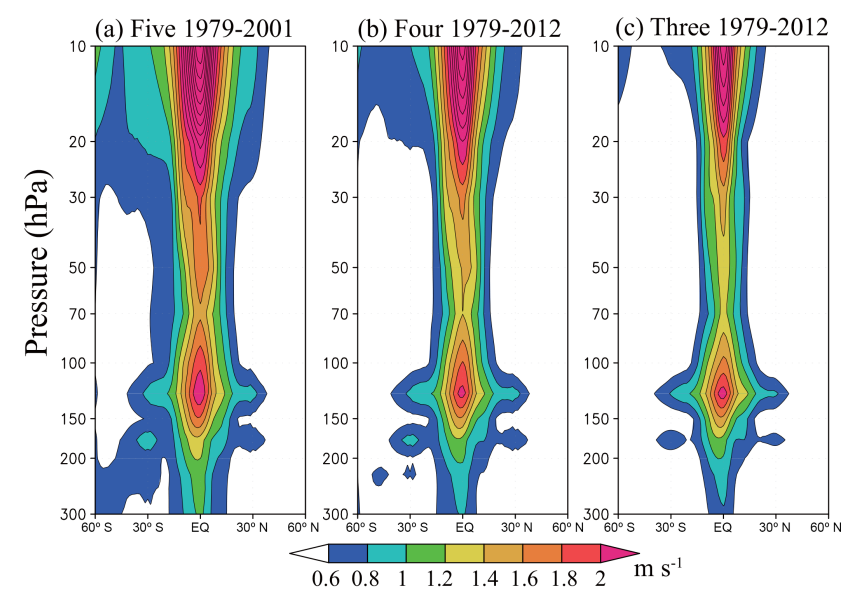

Figure 3. Latitude-height cross sections of zonal mean and time mean of the standard deviation among (a) five reanalyses of ERA40, ERA-I, JRA-25, JRA-55, and MERRA from 1979 to 2001; (b) four reanalysis of ERA-I, JRA-25, JRA-55, and MERRA from 1979 to 2012; and (c) three reanalysis of ERA-I, JRA-55, and MERRA from 1979 to 2012 . The color intervals are $0.2 \mathrm{~m} \mathrm{~s}^{-1}$ and shaded with values larger than $0.6 \mathrm{~m} \mathrm{~s}^{-1}$.

the next section. In any case, the distributions of the SD are quite similar.

In order to examine the SD in more detail later, the SD is divided into zonal mean components $(\bar{u}$; overbar denotes the zonal mean) and components of deviation from zonal mean $\left(u^{\prime}\right.$ : hereafter, referred to as eddy components). Substituting $u_{i}=\bar{u}_{i}+u_{i}^{\prime}$ and $[u]=[\bar{u}]+\left[u^{\prime}\right]$ in Eq. (1) and taking the zonal mean yields:

$\overline{(\mathrm{SD})^{2}}=\sum_{i}^{N} \overline{\left(\bar{u}_{i}-[\bar{u}]\right)^{2}} / N+\sum_{i}^{N} \overline{\left(u_{i}^{\prime}-\left[u^{\prime}\right]\right)^{2}} / N$.

Here, the first term on the right side represents the zonal mean variance among reanalyses due to the zonal mean wind component and second term exhibits the zonal mean variance attributable to eddy components.

Figure 4 shows horizontal distributions of the SD at 10, $20,30,50$, and $70 \mathrm{hPa}$. At $50-70 \mathrm{hPa}$, large $\mathrm{SD}$ is seen in the Indian Ocean, to the east of the maritime continent, the Atlantic, and especially in the central Pacific. At $10-30 \mathrm{hPa}$, however, the SD becomes more zonally uniform with increasing height.

\subsection{Dependence in the lower stratosphere}

Satellite radiance observations are distributed much more uniformly and homogeneously than in situ balloon observations, so it might be expected that satellite data assimilation would not have a large effect on the spatial distribution of the SD among reanalyses. We may expect the SD geographical distributions to be related primarily to the availability of station observations. Figure 5a shows the locations of all (a) SD 10hPa 1979-2001

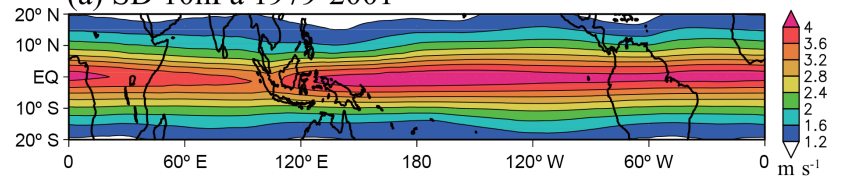

(b) SD 20hPa 1979-2001

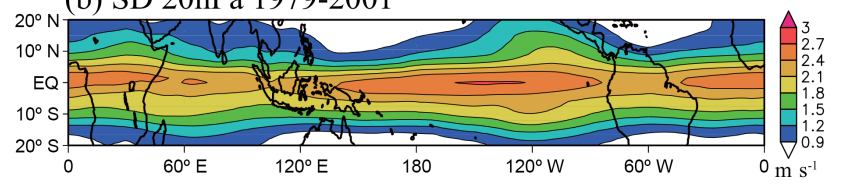

(c) SD 30hPa 1979-2001
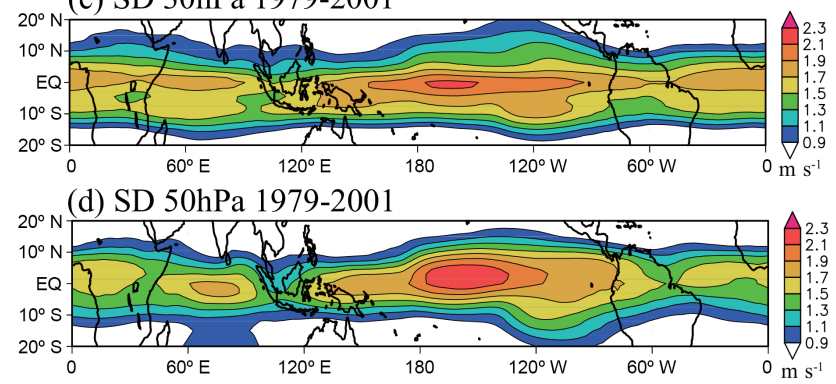

(e) SD 70hPa 1979-2001

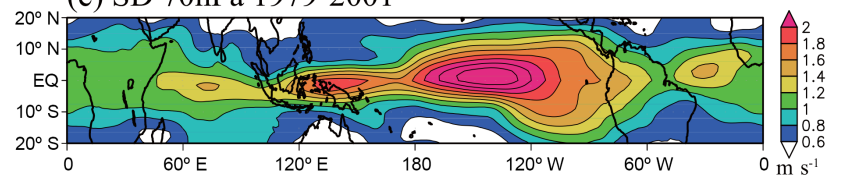

Figure 4. Horizontal maps of the standard deviation among the five reanalyses at (a) $10 \mathrm{hPa}$, (b) $20 \mathrm{hPa}$, (c) $30 \mathrm{hPa}$, (d) $50 \mathrm{hPa}$, and (e) $70 \mathrm{hPa}$. The color intervals are $0.4 \mathrm{~m} \mathrm{~s}^{-1}$ for (a), $0.3 \mathrm{~m} \mathrm{~s}^{-1}$ for (b), and $0.2 \mathrm{~m} \mathrm{~s}^{-1}$ for (c-e). Color ranges are different among these heights.

radiosonde stations in the IGRA (magenta dots indicate the locations of the stations shown later in Fig. 6). We calculated the fraction of months during 1979-2001 with valid monthly-mean wind data at each level at each IGRA station. Figure $5 b-f$ display the fractional data coverage at each radiosonde station with at least some useful data from 10 to $70 \mathrm{hPa}$ (the $100 \%$ coverage of Singapore in the FUB data is also indicated). The contours in these panels reproduce the values of the SD shown in Fig. 4. Over $10^{\circ} \mathrm{N}-10^{\circ} \mathrm{S}$, there are about 220 radiosonde stations (Fig. 5a), but only a fairly small fraction have significant data coverage at the stratospheric levels of interest here, particularly at $10 \mathrm{hPa}$.

At $50-70 \mathrm{hPa}$, distributions of the SD appear to be negatively correlated with the density of radiosonde observations. The SD shows the local minima in the zonal direction near the locations with high observational density, such as the vicinity of Sumatra, Borneo and the Malay Peninsula, and over much of South America. Large SD values are found over an extensive region in the eastern and central Pacific where few radiosonde observations are available.

Observational information is propagated with time and space through analysis steps and forecast steps in data assimilation. In analysis steps, the background error covari- 
(a) Radiosonde observational points

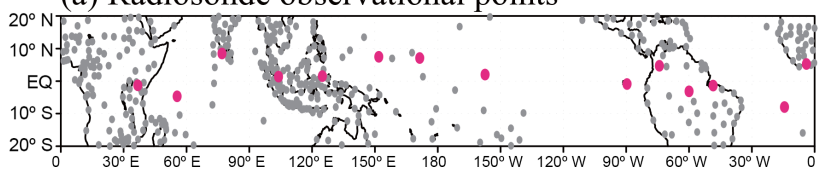

(b) $10 \mathrm{hPa}$ observational coverage 1979-2001

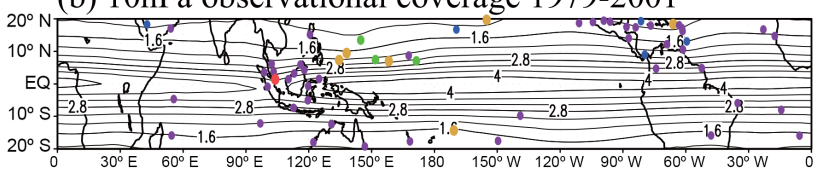

(c) $20 \mathrm{hPa}$ observational coverage $1979-2001$

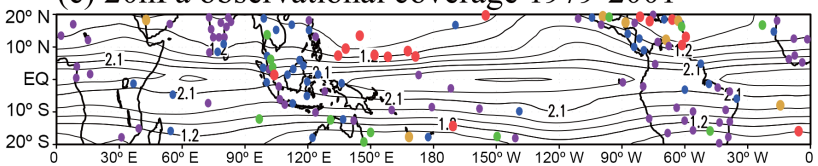

(d) $30 \mathrm{hPa}$ observational coverage 1979-2001

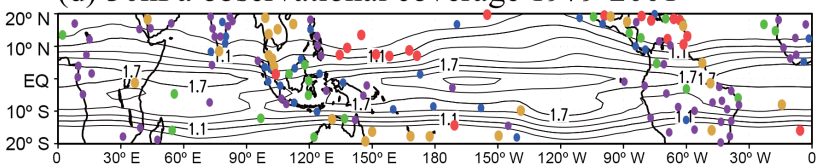

(e) $50 \mathrm{hPa}$ observational coverage 1979-2001

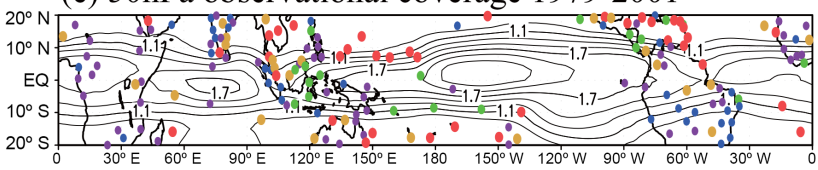

(f) $70 \mathrm{hPa}$ observational coverage 1979-2001

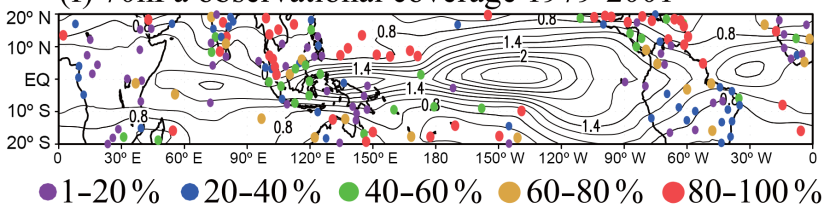

Figure 5. (a) Locations of all IGRA stations in the tropical region (magenta dots indicate the locations of the stations shown in Fig. 6). (b-f) IGRA stations with data coverage of (purple) 1-20\%, (blue) $20-40 \%$, (green) $40-60 \%$, (yellow) $60-80 \%$, and (red) 80 $100 \%$ at (b) 10 , (c) 20, (d) 30, (e) 50, and (f) $70 \mathrm{hPa}$ during 19792001. The contours show the standard deviation among reanalyses as shown in Fig. 4. The contour intervals at each height are the same as in Fig. 4.

ance matrix is used to determine the spatial structure and the magnitude of analysis increment. Advanced data assimilation techniques such as 4D-VAR (used in JRA-55 and ERAI) are expected to provide more efficient constraints even for remote points, because of the use of flow-dependent analysis. The different data assimilation methods used in each reanalysis would contribute to the SD even if each reanalysis assimilated the same observational data. In addition, the SD may also reflect differences among the climatologies of the GCMs used in the analysis systems.

Next, we consider the time variations of the spread among reanalyses at individual places and its relation to the availability of local radiosonde data. Each panel in Fig. 6 shows the time variations of monthly-mean $70 \mathrm{hPa}$ zonal wind mea- sured at a particular radiosonde station together with the values from each of the five reanalyses and the SD among the reanalyses. The blue/red colors of the SD curves in each panel denote times with/without radiosonde data at the station. In the upper right corner of each bottom panel, the total data coverage (black number) and the average value of the SD during periods with (blue number) and without (red number) radiosonde data at each station are shown.

At data-rich stations with coverage $\geq 80 \%$ such as Thiruvananthapuram (Fig. 6c), Singapore (Fig. 6d), Chuuk (Fig. 6f), Majuro (Fig. 6g), and Ascension (Fig. 6m), reanalyses zonal winds generally agree well with the direct observations, and the SD among reanalyses is small. However, on Christmas Island (Fig. 6h), where no observational data are available from these 23 years, the SD is large throughout the record. There are no other stations with available data near Christmas Island (Fig. 5a), which may also contribute to the extended period of large SD there.

Menado (Fig. 6e) and San Cristobal (Fig. 6i) demonstrate that the reanalysis SD at the locations of near-equatorial stations (within $1.5^{\circ}$ of the Equator; Fig. 5a) can be appreciably reduced during times when radiosonde data from these stations are available. Bogota (Fig. 6j) and Manaus (Fig. 6k) are good examples off the Equator also showing smaller SD during months with balloon data than without these data.

At Nairobi (Fig. 6a), an unrealistic spike in the westerlies is apparent in the observed record for January 1981, but none of the reanalyses replicate this spike. This might be an example of data quality control (e.g., gross error check based on observation-minus-forecast departures statistics) removing observational data during the assimilation processes. In the evolution from late 1997 to early 1998, the direct observations at most stations indicate double westerly peaks, but the second peak, in early 1998, was not observed at Abidjan (Fig. 6n). ERA-I and ERA-40 data follow this pattern and indicate a single peak but JRA-25, JRA-55, and MERRA display double peaks. Consequently the SD has a local maximum during this period. These results suggest that the error check procedures or assimilation schemes employed in the different centers may respond differently to anomalous single station observations.

The correspondence between periods of availability of radiosonde data and SD values among the reanalyses is sometimes unclear, such as at Seychelles (Fig. 6b), for 1980-1982 at Belem (Fig. 61), and for 1984-1998 at Abidjan (Fig. 6n). However in general, the SD in Fig. 6 is smaller during the months when radiosonde observations are available, and the SD tends to be larger when they are not available. These results suggest that the observations at these individual stations are having a significant influence constraining the reanalyses of the zonal wind in the tropical lower stratosphere.

To investigate what affects the longitudinal SD variation from the upper troposphere to the lower stratosphere, Fig. 7 shows the longitude-height cross section of zonal wind averaged over the five reanalyses and their SDs (both averaged 
(a) Nairobi (37E, 1.3S)

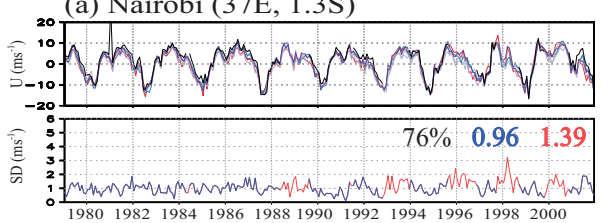

(c) Thiruvananthapuram $(77 \mathrm{E}, 8.5 \mathrm{~N})$

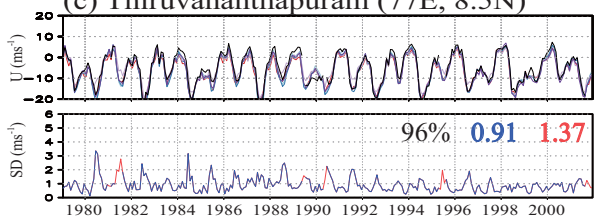

(e) Menado (125E, $1.5 \mathrm{~N})$

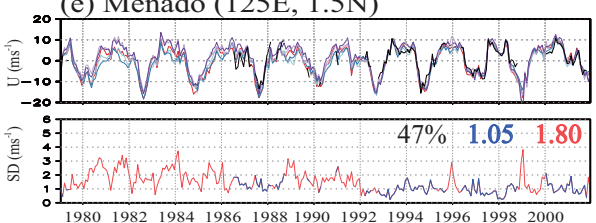

(g) Majuro $(171 \mathrm{E}, 7.1 \mathrm{~N})$
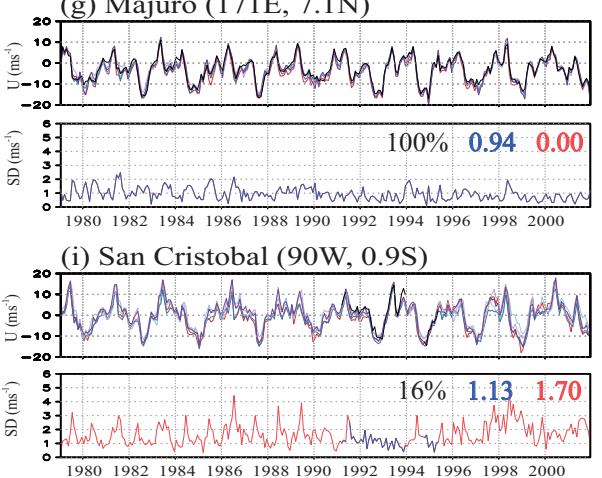

(k) Manaus $(60 \mathrm{~W}, 3.2 \mathrm{~S})$

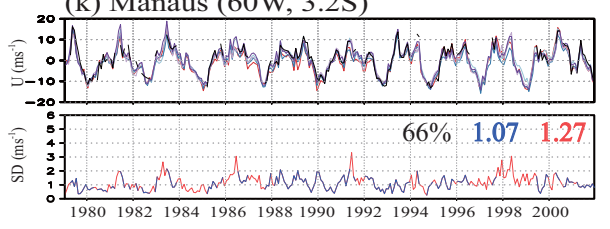

(m) Ascension (14W, 8.0S)

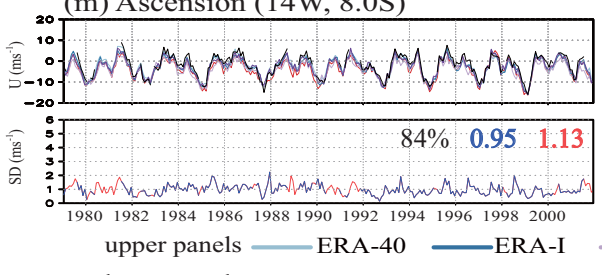

lower panels SD when IGRA available (b) Seychelles $(56 \mathrm{E}, 4.7 \mathrm{~S})$
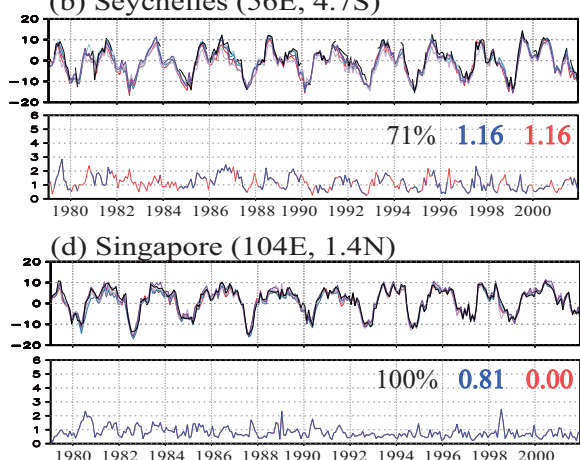

(f) Chuuk $(152 \mathrm{E}, 7.5 \mathrm{~N})$

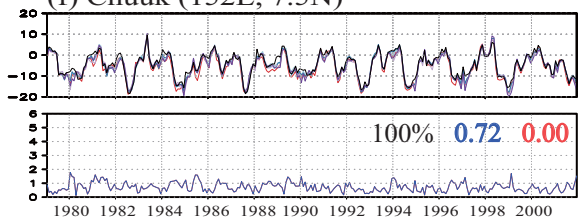

(h) Christmas $(157 \mathrm{~W}, 2.0 \mathrm{~N})$
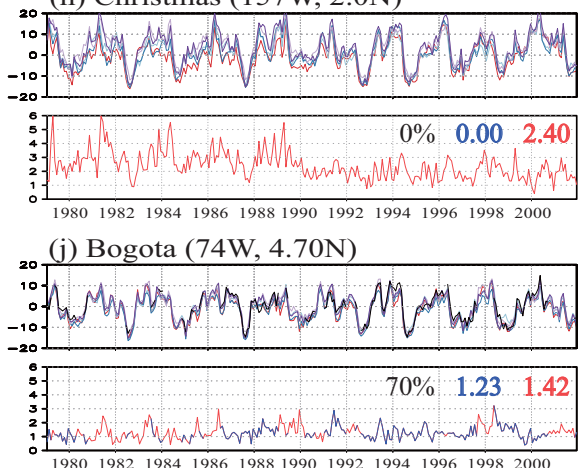

(1) Belem $(48 \mathrm{~W}, 1.4 \mathrm{~S})$

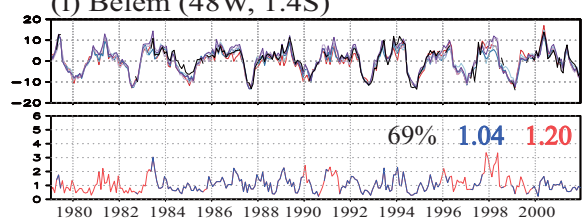

(n) Abidjan $(4 \mathrm{~W}, 5.3 \mathrm{~N})$

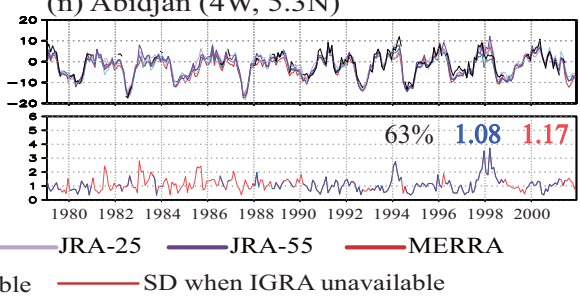

Figure 6. Upper panels show observed zonal wind (black) at each station and reanalysis zonal wind (color) at $70 \mathrm{hPa}$ interpolated to each observational point from 1979 to 2001 . Lower panels depict standard deviation among the five reanalyses at $70 \mathrm{hPa}$. Blue lines show the standard deviation during times when monthly-mean radiosonde data are available and red lines show the standard deviation during times when they are not. In the upper right corner of each bottom panel, the total data coverage (\%) at each station and the average value of the standard deviation during periods with (blue number) and without (red number) radiosonde data are shown.

over the 1979-2001 period), as well as the temporal correlation for the period 1979-2001 between the absolute value of the zonal wind (i.e., the strength of the zonal wind, $|[u]|)$ and the SD. All panels show the $10^{\circ} \mathrm{N}-10^{\circ} \mathrm{S}$ average. Figure $7 \mathrm{a}$ displays the familiar Walker circulation signal in prevailing zonal winds in the upper troposphere. Figure 7a suggests the eddy components of the prevailing zonal wind at $70 \mathrm{hPa}$ (and to some extent even at $50 \mathrm{hPa}$ ) can be regarded as part 
(a) Average zonal wind $10^{\circ} \mathrm{S}-10^{\circ} \mathrm{N} 1979-2001$
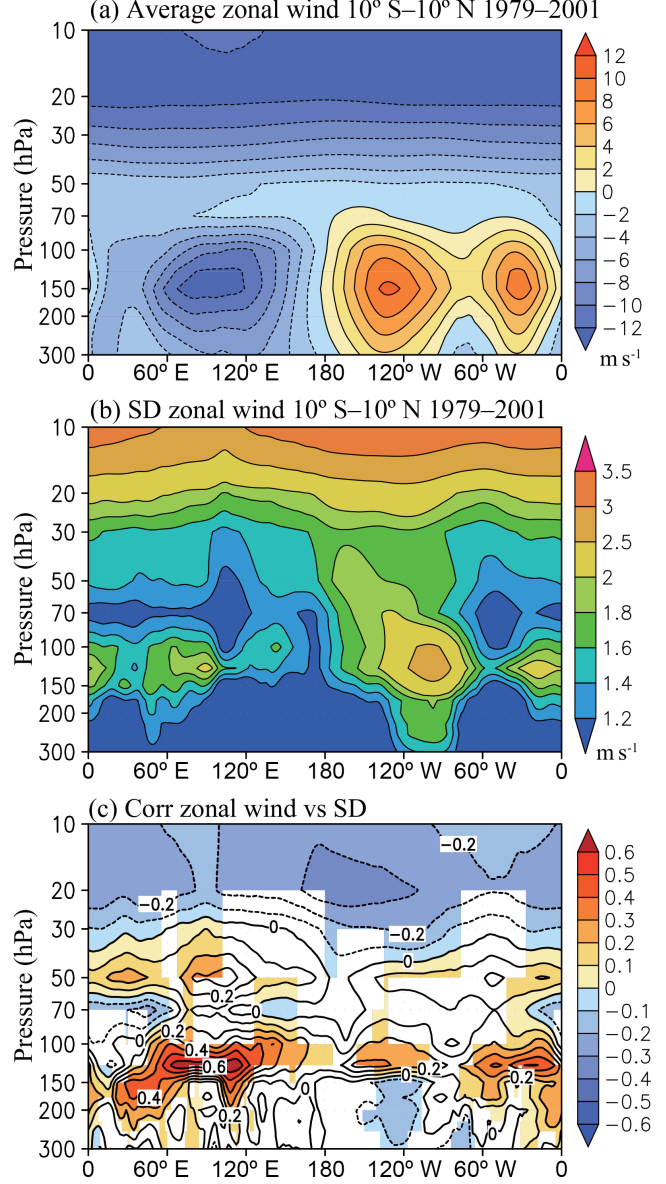

Figure 7. Longitude-height cross section of (a) averaged zonal wind in the five reanalyses, (b) the standard deviation among reanalysis, and (c) the correlation between absolute value of zonal wind and the standard deviation in $10^{\circ} \mathrm{N}-10^{\circ} \mathrm{S}$ averaged from 1979 to 2001. The color intervals are (a) $2 \mathrm{~m} \mathrm{~s}^{-1}$, (b) $0.2 \mathrm{~m} \mathrm{~s}^{-1}$ for values less than $2 \mathrm{~m} \mathrm{~s}^{-1}$ and $0.5 \mathrm{~m} \mathrm{~s}^{-1}$ for values more than $2 \mathrm{~m} \mathrm{~s}^{-1}$, and (c) 0.1 , with statistical significance of $\geq 95 \%$ colored.

of the Walker circulation. Hamilton et al. (2004) showed in their general circulation model experiments that, below about $60 \mathrm{hPa}$, the deviation of the zonal wind from the zonal mean appears to be dominated by an extension of the tropospheric Walker circulation.

A zonally elongated region of large SD exists around 100$150 \mathrm{hPa}$, the upper part of the Walker circulation (Fig. 7b). This upper-tropospheric SD is largest in the central Pacific, where few observational stations are located (Fig. 5a). It is interesting that the region of large SD around the central Pacific in the upper troposphere connects with that seen in the lower stratosphere.

The correlation between the absolute value of zonal wind and the SD among reanalyses shows relatively high positive correlation in the upper part of the Walker circulation in the eastern hemisphere, while the correlation is relatively low in the central Pacific (Fig. 7c). In the mean state, the eddy com- ponent in the tropical lower stratosphere might be associated with an extension of the Walker circulation, but $70 \mathrm{hPa}$ SD is relatively small, and it does not seem correlated with the strength of the upper-tropospheric Walker circulation. The large SD from the upper troposphere to the stratosphere in the central Pacific could be simply related to the fewer in situ observations available there. In the middle stratosphere, the correlation is negative, indicating that the reanalyses disagree the most when the magnitude of the zonal wind is weakest. This corresponds to large SD during the phase transition of the QBO, as shown in the next section.

\subsection{Differences in the middle stratosphere}

In this subsection we discuss the SD at $10-30 \mathrm{hPa}$ where generally fewer radiosonde observations are available. At 20-30 hPa, the SD becomes more zonally uniform compared with results at 50-70 hPa (Fig. 4). However, relatively higher-density observations around the Indonesian maritime continent, as well as over the North and South American and African continents, do act to reduce the SD locally (Fig. 5c and d). At $10 \mathrm{hPa}$, Singapore is the only station quite near the Equator with high-density coverage, and several stations around $7-10^{\circ} \mathrm{N}$ in the western Pacific have data coverage of 40-80\% (Fig. 5b).

Because the SD among reanalyses involves more zonally uniform structures in the middle stratosphere (Fig. 4), the zonally averaged SD is investigated first. Figure 8 shows zonal mean equatorial zonal wind in each reanalysis plotted together with the zonally averaged SD among reanalysis at 10,20 , and $30 \mathrm{hPa}$. Large differences are seen when the QBO phase changes from easterly to westerly. In addition, the SD is generally larger during the westerly phase than during the easterly phase of the QBO. The dependence of SD on the QBO phase is most pronounced at $10 \mathrm{hPa}$.

To further investigate this dependence, a zonal wind composite based on the phase of the QBO was computed for the FUB observations and for each reanalysis over 19792001. For the easterly-to-westerly composite, the month " 0 " is defined as the final month with a mean easterly value in the $10 \mathrm{hPa}$ FUB data and month " +1 " is the first month with a mean westerly value. Composite values are then computed for \pm 6 months around these zero months (month 0 in August 1979, January 1982, March 1984, etc.) for the easterly-to-westerly phases; see Fig. 2a. A similar westerlyto-easterly composite was also computed (with month 0 taken at June 1980, January 1983, June 1985, etc.). We chose $10 \mathrm{hPa}$ as presenting the biggest challenge for the reanalyses as the numbers of radiosonde observations are fewest and the $\mathrm{SD}$ among reanalyses is largest.

The QBO composites for the zonal wind at $10 \mathrm{hPa}$ are shown in Fig. 9a-d. Results for the zonal wind in Singapore are shown in the left panels (a and c) while results for the zonal mean equatorial zonal wind are shown in the right panels ( $b$ and $d)$. Through the easterly-to-westerly transition in 

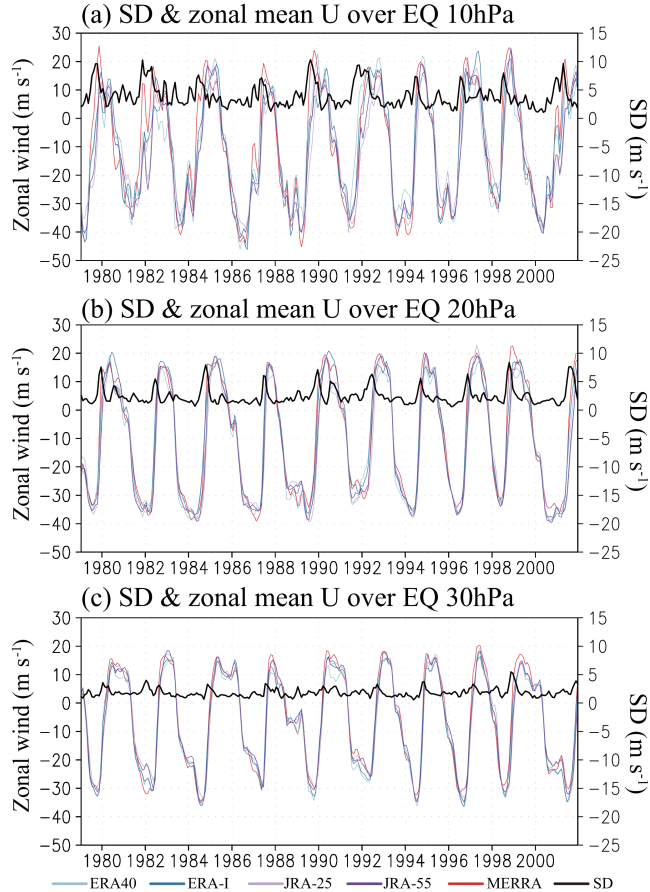

Figure 8. Zonal mean equatorial zonal wind in each reanalysis (colors) and zonally averaged equatorial standard deviation among reanalyses (black) at (a) 10, (b) 20, and (c) $30 \mathrm{hPa}$.

Singapore (Fig. 9a), the composite zonal winds in most of the reanalyses have an easterly bias relative to the FUB observations particularly during months -1 to +3 . This results in a delay in the time of the zero-crossing in the reanalyses relative to the FUB observations. The reanalyses differ considerably in terms of this bias, however. The delay is $\sim 1.5-$ 2 month in JRA-25 and JRA-55 and $\sim 0.5$ month in ERA-40 and ERA-I. The MERRA zonal winds show good agreement with FUB data during the easterly-to-westerly transition. The zonal wind values in the reanalyses show better agreement with the FUB observations and closer agreement among themselves during the westerly-to-easterly phase transition (Fig. 9c).

In composites of the zonal mean zonal wind (Fig. 9b, d), during the 6 months following the transition date the maximum westerly in each reanalysis is slightly smaller than in the zonal wind over Singapore $\left(\sim 3-4 \mathrm{~m} \mathrm{~s}^{-1}\right.$ for ERA-40 and ERA-I, $\sim 2-3 \mathrm{~m} \mathrm{~s}^{-1}$ for JRA-25 and JRA-55, nearly the same for MERRA), while the maximum easterly is nearly same. In both phase transitions, the spread of reanalysis zonal mean zonal winds is larger than that over Singapore. It should be noted that the timing of both phase transitions in the zonal mean is generally the same as those seen just using results in Singapore (although there is a slight delay of $\sim 0.5$ months in the easterly-to-westerly transition of the zonal mean in the JRA-25 and JRA-55).
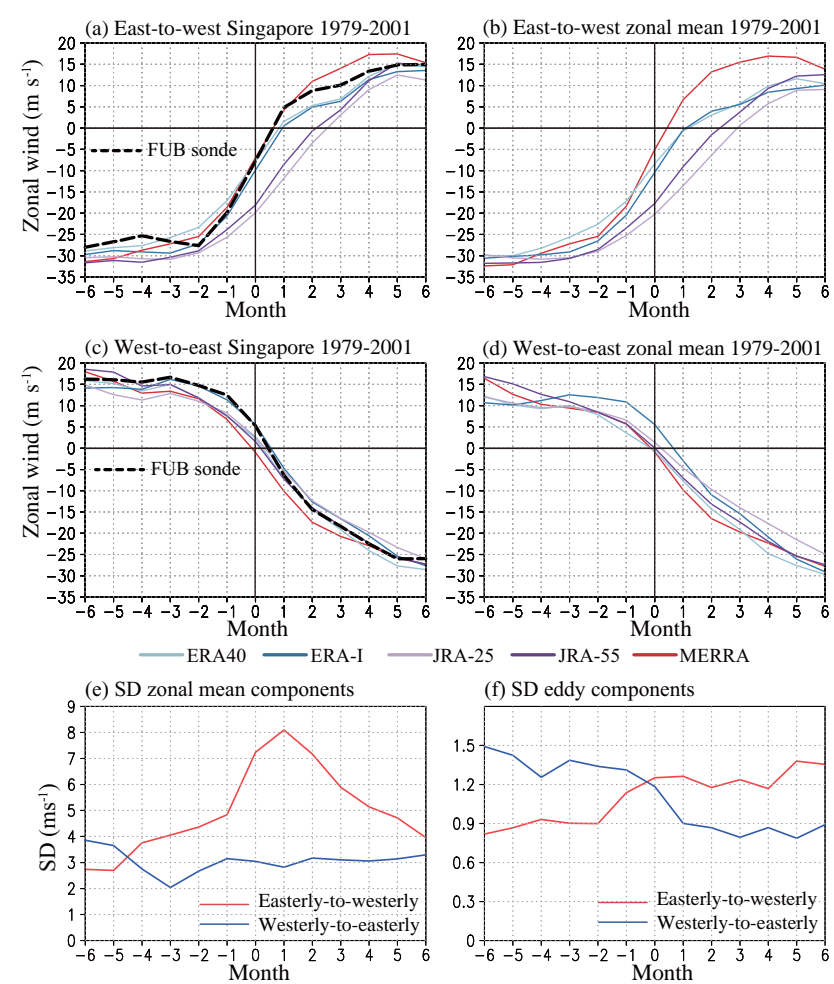

Figure 9. Top: composite of the QBO in the zonal wind at $10 \mathrm{hPa}$ during 1979 to 2001 where month 0 corresponds to $(\mathbf{a}, \mathbf{b})$ the easterly-to-westerly transition of the FUB zonal wind at $10 \mathrm{hPa}$ and to (c, d) the westerly-to-easterly transition. Color lines show each reanalysis zonal wind, and black dashed lines depict FUB zonal wind in Singapore. Results for $(\mathbf{a}, \mathbf{c})$ the zonal wind in Singapore and for $(\mathbf{b}, \mathbf{d})$ the zonal mean equatorial zonal wind. Bottom: composite of the zonal mean equatorial standard deviation due to (e) zonal mean and (f) eddy components during (red) easterly-towesterly and (blue) westerly-to-easterly transitions at $10 \mathrm{hPa}$. Note the ordinate axes are different between $(\mathbf{e}, \mathbf{f})$.

Figure 9e and f show a QBO composite of the zonal mean equatorial SD among five reanalyses due to zonal mean and eddy components (square roots of the first and second terms on the right in Eq. (2), respectively) at $10 \mathrm{hPa}$. It is clear that the SD due to zonal mean components is large during the phase transition from easterly to westerly, while the SD does not change much during the 12 composite months during the westerly-to-easterly (Fig. 9e). The SD due to eddy components has larger values during the westerly than the easterly phase (Fig. 9f).

It is well known that the transition of the QBO from easterly-to-westerly is considerably faster than that from the westerly-to-easterly (e.g., Baldwin et al., 2001). In other words, the zonal wind tendency $|\partial u / \partial t|$ is larger during the easterly-to-westerly transition. As the QBO could not be simulated without data assimilation from each reanalysis model (except MERRA-2), one possible reason for the large SD in the easterly-to-westerly is weak forcing by resolved waves in 
the reanalysis model, leading to a slow change of the zonal wind and a resulting delay of the phase transition. The results of Fig. 9 suggest that the total observational constraints are insufficient to completely compensate for model bias, resulting in slow change of the zonal wind and delay of the phase transition. The another possibility is that during periods of weak zonal wind there will be delays in the zonal advective propagation of information introduced into the analysis system from observations at individual stations (notably Singapore). We are not able to definitely assess these two possible mechanisms, but the fact that the lag in the reanalysis winds is more pronounced in the more rapid easterly-to-westerly wind transition may favor the importance of the model bias over the slow advective propagation mechanism.

Each reanalysis model may not have sufficiently fine vertical resolution to represent completely the interaction between vertically propagating waves and the mean flow, which is thought to be crucial to the QBO dynamics (e.g., Baldwin et al., 2001), because the vertical wavelengths of waves become smaller as they approach critical levels. Podglajen et al. (2014) show vertical profiles of meridional wind by radiosonde observation in Singapore and in ECMWF operational analysis and indicate that ECMWF does not adequately represent wave disturbances due to insufficient vertical resolution (Fig. 9 of their study). MERRA has the finest vertical resolution among five reanalyses in the 20$30 \mathrm{~km}$ layer, which may allow a better representation of wave forcing in the strong vertical shears of the QBO. Kim and Chun (2015) investigate the momentum forcing of the QBO by resolved waves in reanalysis models and show that MERRA has the larger net-resolved wave forcing than ERA-I, MERRA, and JRA-55 (Fig. 2 in their study). They also show that mean residual vertical velocity in the tropics, which generally acts in the opposite sense to wave forcing in driving the zonal wind acceleration (e.g., Kawatani et al., 2011), is much smaller in MERRA than in other reanalyses (Fig. 5a in their study). These are possible reasons why the MERRA shows faster transitions both in easterly-to-westerly and westerly-to-easterly transitions compared with those in the other reanalyses.

Next we will discuss the representation of eddy components of the wind in the reanalysis data sets. Figure $10 \mathrm{a}-\mathrm{e}$ show $u^{\prime}$, the deviation of the monthly-mean zonal wind values from the zonal mean, at $10 \mathrm{hPa}$ for each reanalysis in January 1999, during the westerly phase of the QBO. In all the reanalyses the eddy component near the Equator appears to be dominated by zonal wavenumber 1 and 2 quasi-stationary planetary waves propagating from midlatitudes, but the patterns differ somewhat among the reanalyses. For example, ERA-40 shows a large, local, positive anomaly to the east of the Indonesian maritime continent, while JRA-55 does not. Each reanalysis shows a different shape for this positive anomaly. In addition, the negative anomalies around the Bay of Guinea and central Pacific are also different.

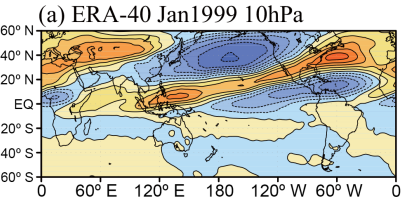

(b) ERA-I Jan1999 10hPa

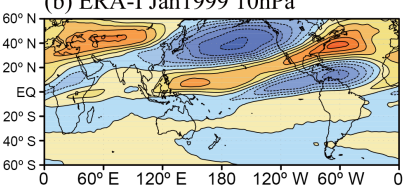

(c) JRA-25 Jan1999 10hPa

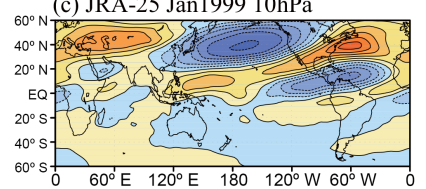

(d) JRA-55 Jan1999 10hPa

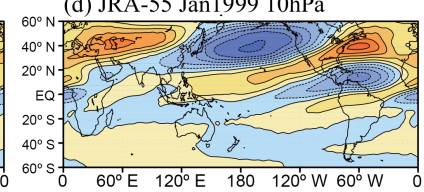

(e) MERRA Jan1999 10hPa

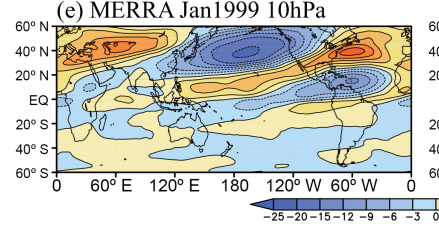

(f) ERA-I Jan1996 10hPa
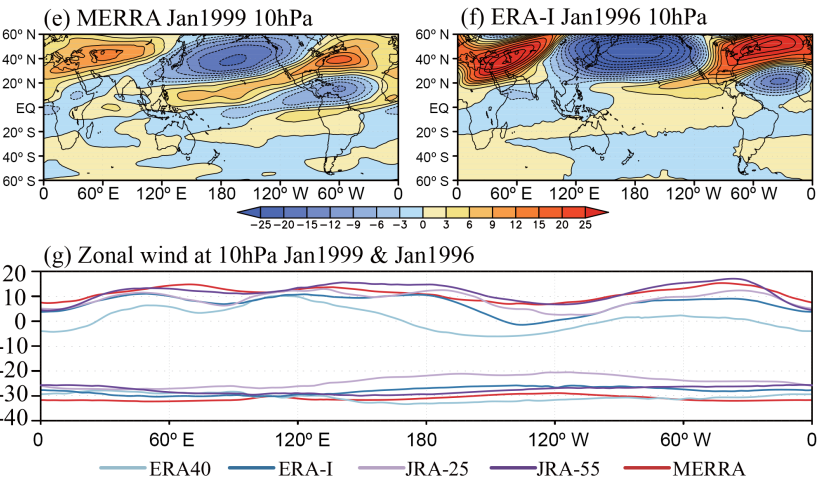

Figure 10. Deviation of the zonal wind values from the zonal mean $\left(u^{\prime}\right)$ at $10 \mathrm{hPa}$ of (a-e) five reanalyses in January 1999 during the westerly phase and (f) of the ERA-I in January 1996 during the easterly phase of the QBO. The color interval is $\pm 3,6,9,12,15$, 20 , or $25 \mathrm{~m} \mathrm{~s}^{-1}$. (g) Longitudinal variations of the zonal wind of each reanalysis at $10 \mathrm{hPa}$ over the Equator in January 1999 and January 1996.

Figure 10f shows one example of the eddy components of the zonal wind in January 1996, during the easterly phase of the QBO in ERA-I. The eddy components are very small over the Equator, which is expected as stationary planetary waves cannot propagate into the equatorial mean easterlies. Figure $10 \mathrm{~g}$ depicts the longitudinal variations of each reanalysis zonal wind at $10 \mathrm{hPa}$ over the Equator in January 1996 and 1999. It is clear that the spread of the zonal wind among reanalyses is larger in the westerly phase, and longitudinal variation of the zonal wind is smaller in the easterly phase. We have checked other periods and found the monthlymean eddy structures in the middle stratosphere associated with quasi-stationary planetary waves are qualitatively similar among years (not shown). The large contribution to SD from eddy components during the westerly phase of the QBO (Fig. 9f) mainly results from different representation of midlatitude planetary waves propagating into the Equator among reanalyses.

\subsection{Difference depending on the QBO phase}

In this subsection, we investigate the dependence of the SD among the reanalyses on the QBO phase. We have computed the SD separately for the westerly and easterly phases 
of the QBO defined by the sign of the five reanalyses averaged zonal mean zonal wind at the Equator (i.e., defined as $[\bar{u}]_{\mathrm{eq}}>0$ for the westerly and $[\bar{u}]_{\mathrm{eq}}<0$ for the easterly phase; subscript $e q$ indicates the Equator). Figure 11a and $\mathrm{b}$ are maps of the SD among reanalyses at $10 \mathrm{hPa}$ during the westerly and easterly phases of the QBO for 1979-2001. Figure $11 \mathrm{c}-\mathrm{g}$ plot the zonal variation of the SD averaged over $10^{\circ} \mathrm{S}-10^{\circ} \mathrm{N}$ at each height in the easterly and westerly QBO phases. At $10 \mathrm{hPa}$, large SD values in the westerly phase are seen in the Pacific and from the Atlantic to Africa, where representations of quasi-stationary planetary waves differ significantly among the reanalyses (see Fig. 10). However, in the easterly phase, the SD is more zonally uniform. It is interesting that, both in the westerly and easterly phases, the SD declines significantly around the longitudes near Singapore. At $10 \mathrm{hPa}$ the Singapore station provides the only continuous record of in situ data near the Equator (Fig. 5b), and the results in Fig. 11c suggest that observations from this one station act as a strong constraint on the reanalyses.

The overall larger SD in the westerly QBO phases, as compared to the easterly QBO phases, especially over the Pacific, is still clear at $20 \mathrm{hPa}$ (Fig. 11d). However, this feature is not apparent at $30 \mathrm{hPa}$ (Fig. 11e), suggesting that the effects of quasi-stationary planetary waves become much smaller at $30 \mathrm{hPa}$. At $50 \mathrm{hPa}$, the SD in the westerly and easterly phases is nearly identical (Fig. 11f). At $70 \mathrm{hPa}$ the longitudinal variation of the SD in the westerly phase is similar to that in the easterly phase (Fig. 11g). This indicates that the QBO phase is not very important for SD zonal variations in the lower stratosphere.

\section{Evolution of the differences among reanalyses with time}

In this section, we discuss how the SD among reanalyses changes with time as the in situ and remote data sources available for the reanalyses evolve. We will show the results from the four reanalyses data sets (ERA-I, JRA-25, JRA-55, and MERRA) that exist over the entire 34 year period 1979 to 2012. Figure 12a-c are maps of the SD averaged over 50$70 \mathrm{hPa}$ for three 11-year intervals: 1979-1989, 1990-2000, and 2001-2011. The SD among reanalyses reduces significantly with time, but it is interesting that geographical distributions of the SD remain quite similar over these three periods.

The left panels in Fig. 13 show time variations of zonal mean SD among the four reanalyses at each height averaged over $10^{\circ} \mathrm{S}-10^{\circ} \mathrm{N}$. At 50 and $70 \mathrm{hPa}$ (Fig. $13 \mathrm{j}, \mathrm{m}$ ), the overall level of SD reduces gradually in the 1980s and 1990s, and a clear drop is found around 1998 at $50 \mathrm{hPa}$. At $10-30 \mathrm{hPa}$ (Fig. 13a, d, g), the SD also reduces with time, but a sudden drop is not apparent.

The middle panels in Fig. 13 plot the same quantity as the left panels, but for the SD due to zonal mean and eddy
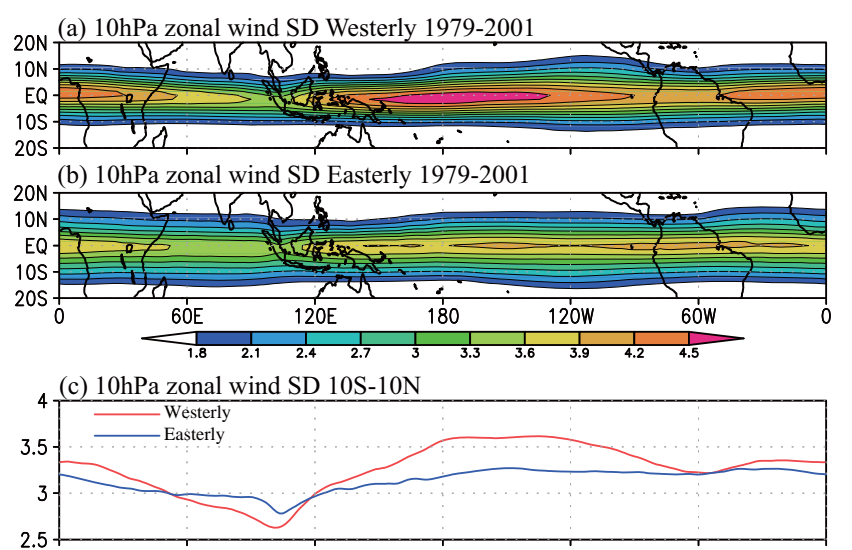

(d) $20 \mathrm{hPa}$ zonal wind SD $10 \mathrm{~S}-10 \mathrm{~N}$
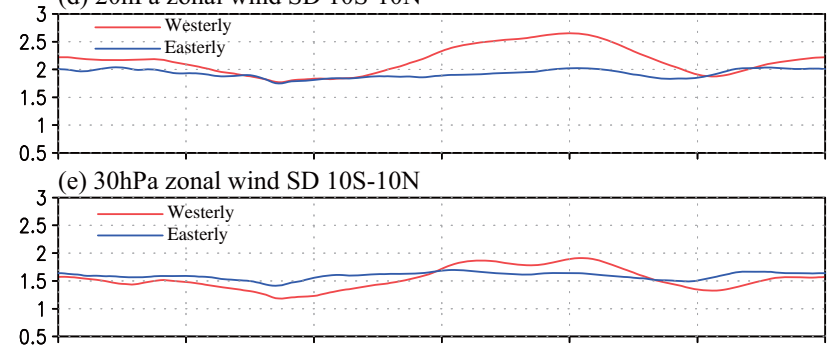

(f) $50 \mathrm{hPa}$ zonal wind SD $10 \mathrm{~S}-10 \mathrm{~N}$

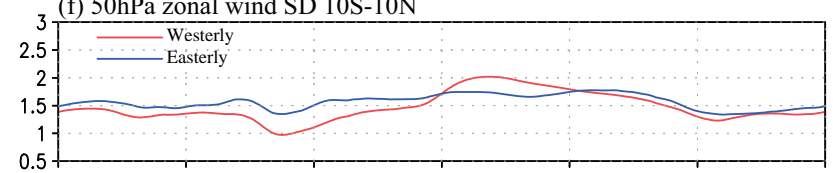

3 (g) $70 \mathrm{hPa}$ zonal wind SD $10 \mathrm{~S}-10 \mathrm{~N}$

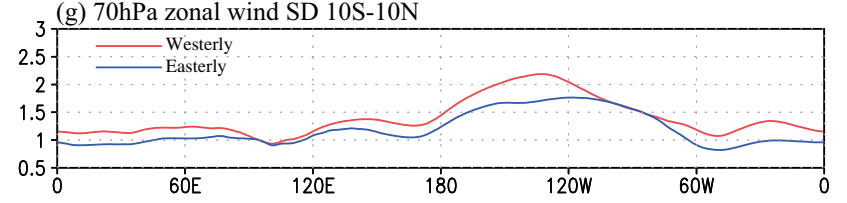

Figure 11. Horizontal distributions of the standard deviation among reanalyses at $10 \mathrm{hPa}$ during the (a) westerly and (b) easterly phase of the QBO averaged in the period 1979-2001. The color interval is $0.3 \mathrm{~m} \mathrm{~s}^{-1}$. Longitudinal variations of the standard deviation at $10^{\circ} \mathrm{S}-10^{\circ} \mathrm{N}$ in (red) westerly and (blue) easterly phase at (c) 10 , (d) 20, (e) 30, (f) 50, and (g) $70 \mathrm{hPa}$.

components separately. At $70 \mathrm{hPa}$ (Fig. 13n), eddy components are comparable to zonal mean components for all periods, and both components reduce gradually with time until $\sim 2000$. The typical level of SD in both components remains fairly constant after 2000 . At $50 \mathrm{hPa}$, the drop of SD in the zonal mean components around 1998 is pronounced; the eddy components also appear to become somewhat smaller after $\sim 1998$.

At $10-30 \mathrm{hPa}$, zonal mean contribution to SD always dominates, but gradually reduces with time (Fig. 13b, e, h). However, throughout the record this quantity spikes generally near a particular phase of the QBO (i.e., during the easterlyto-westerly phase transition). The eddy contribution to SD also reduces slightly with time but not dramatically. 
(a) SD 50-70hPa 1979-1989

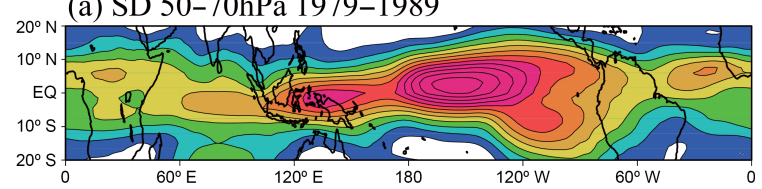

(b) SD 50-70hPa 1990-2000
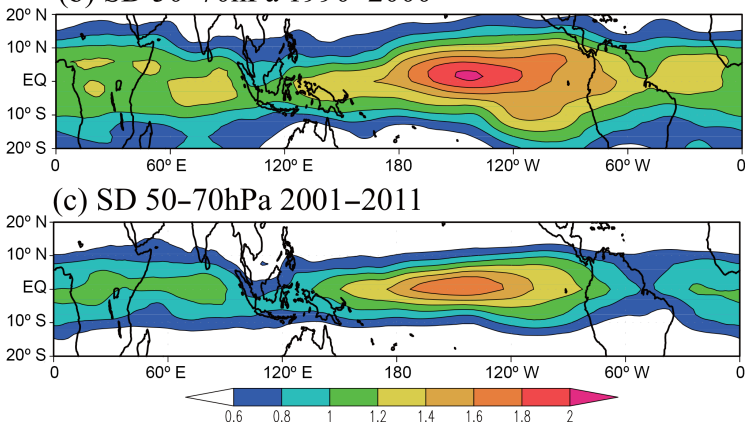

Figure 12. Standard deviation among four reanalyses (ERA-I, JRA25, JRA-55, and MERRA) at 50-70 hPa for each 11-year mean: (a) 1979-1989, (b) 1990-2000, and (c) 2001-2011. The color intervals are $0.2 \mathrm{~m} \mathrm{~s}^{-1}$.

One possible reason for reduction of the zonal wind SD over time would be the upgrading of satellite radiance observations. From 1979 to 2006, the TOVS (TIROS (Television InfRrared Operational Satellite) Operational Vertical Sounder) Stratospheric Sounding Unit (SSU) and Microwave Sounding Unit (MSU) were available. After May 1998, data from the Advanced Microwave Sounding Unit (AMSU) became available. The advent of these new satellite measurements is a possible reason for the decline in the SD around 1998.

Figure 14a shows the time-height section of zonal mean $\mathrm{SD}$ of temperature among the four reanalyses. A large SD is found around $30-50 \mathrm{hPa}$, and this SD reduces significantly after $\sim 1998$. The JRA team has reported on stratospheric temperature issues with JRA-25 and discussed the cause of the biases (Onogi et al., 2007). Fujiwara et al. (2015) explained that the radiative scheme used in the JRA-25 forecast model has a known cold bias in the stratosphere, and the TOVS SSU/MSU measurements do not have a sufficient number of channels to correct the model's cold bias; after introducing the ATOVS AMSU-A measurements in 1998, such a cold bias disappeared in the JRA-25 data product. However, with JRA-55 using a new radiation scheme in the forecast model, the stratospheric temperature during the TOVS period has been much improved.

In light of the possible issues with the JRA-25 temperatures we show in Fig. 14b the temperature SD excluding JRA-25 (i.e., including only ERA-I, JRA-55, and MERRA). When JRA-25 is excluded, the very large SD values over $20-50 \mathrm{hPa}$ before 1998 seen in Fig. 14a are greatly diminished. Even so the temperature SD among the three reanalyses (Fig. 14b) does reduce with time, with an especially large reduction over the full record at 100 and $10 \mathrm{hPa}$. The right panels of Fig. 13 show the same quantity as the left panels but for zonal wind SD among just the ERA-I, JRA-55, and MERRA reanalyses. The SD among the three reanalyses is generally smaller than that among four reanalyses and the dramatic change in zonal wind SD at $50 \mathrm{hPa}$ in 1998 become much weaker with the removal of JRA-25 (Fig. 131), but the time evolution looks very similar.

Figure 15 shows the evolution of the number of available monthly-mean radiosonde observations over $10^{\circ} \mathrm{S}-$ $10^{\circ} \mathrm{N}$ and $10-70 \mathrm{hPa}$. The number of radiosonde observations available generally increased with time at all levels. For example at $70 \mathrm{hPa}(50 \mathrm{hPa})$, the mean number of station months of wind observations was $~ 33.7$ (30.1) in 19791989 , 37.6 (35.1) in 1990-2000, and 44.5 (43.0) in 20012011 (i.e., periods corresponding to those in Fig. 12). So, relative to 1979-1989, the number of radiosonde observations at $70 \mathrm{hPa}(50 \mathrm{hPa})$ increased by $11.6 \%(16.6 \%)$ in 1990 2000 and $32.0 \%(42.9 \%)$ in 2001-2011.

In contrast, the zonal wind SD among the three reanalyses at $10^{\circ} \mathrm{S}-10^{\circ} \mathrm{N}$ (right panels in Fig. 13) and $70 \mathrm{hPa}$ $(50 \mathrm{hPa})$ reduces $20.8 \%(20.4 \%)$ in $1990-2000$ and $33.7 \%$ $(36.3 \%)$ in 2001-2011, compared with those in 1979-1989. The abrupt drop around 1998 is not clearly reflected in the number of radiosonde observations at $50 \mathrm{hPa}$, implying that the AMSU satellite observations could have significant impact on reanalysis of the zonal wind in the tropical stratosphere (see Fig. 13j, 1).

At $10-30 \mathrm{hPa}$, the number of radiosonde observations increased significantly from 1979 to 2012, which should contribute to a reduction of the zonal wind SD with time at these altitudes, in addition to having more satellite data available. The same $10 \mathrm{hPa}$ QBO composites as shown in Fig. 9a-d but during 1998-2012 are illustrated in Fig. 16. Here the zonal wind in ERA-40 is excluded (ERA-40 data exist only up to August 2002) but MERRA-2 is included (the unrealistic features noted earlier in MERRA-2 are not present after 1998). The general features are same as those in 1979-2001 such as an apparent delay in easterly-to-westerly transitions in JRA-25 and JRA-55 compared with the FUB observation and closer agreement among reanalyses in westerly-toeasterly transitions. It should be noted here that in these reanalyses the 10hPa QBO in 1998-2012 are closer to the FUB observations both during easterly-to-westerly and westerlyto-easterly transitions than during 1979-2001 (Fig. 9). In addition, the spread of reanalysis zonal winds become much smaller in the later period, especially for the zonal mean wind. Figure 16 also shows that the MERRA-2 reanalyses display an easterly-to-westerly phase transition in Singapore that is even more rapid than in the direct balloon observations. These results may indicate that the gravity wave sources in MERRA-2 are now excessive (Coy et al., 2016).

Satellite radiance data will presumably affect the assimilated temperatures in the stratosphere but will also have some influence on the wind (cf. Iida et al., 2014), mainly through 

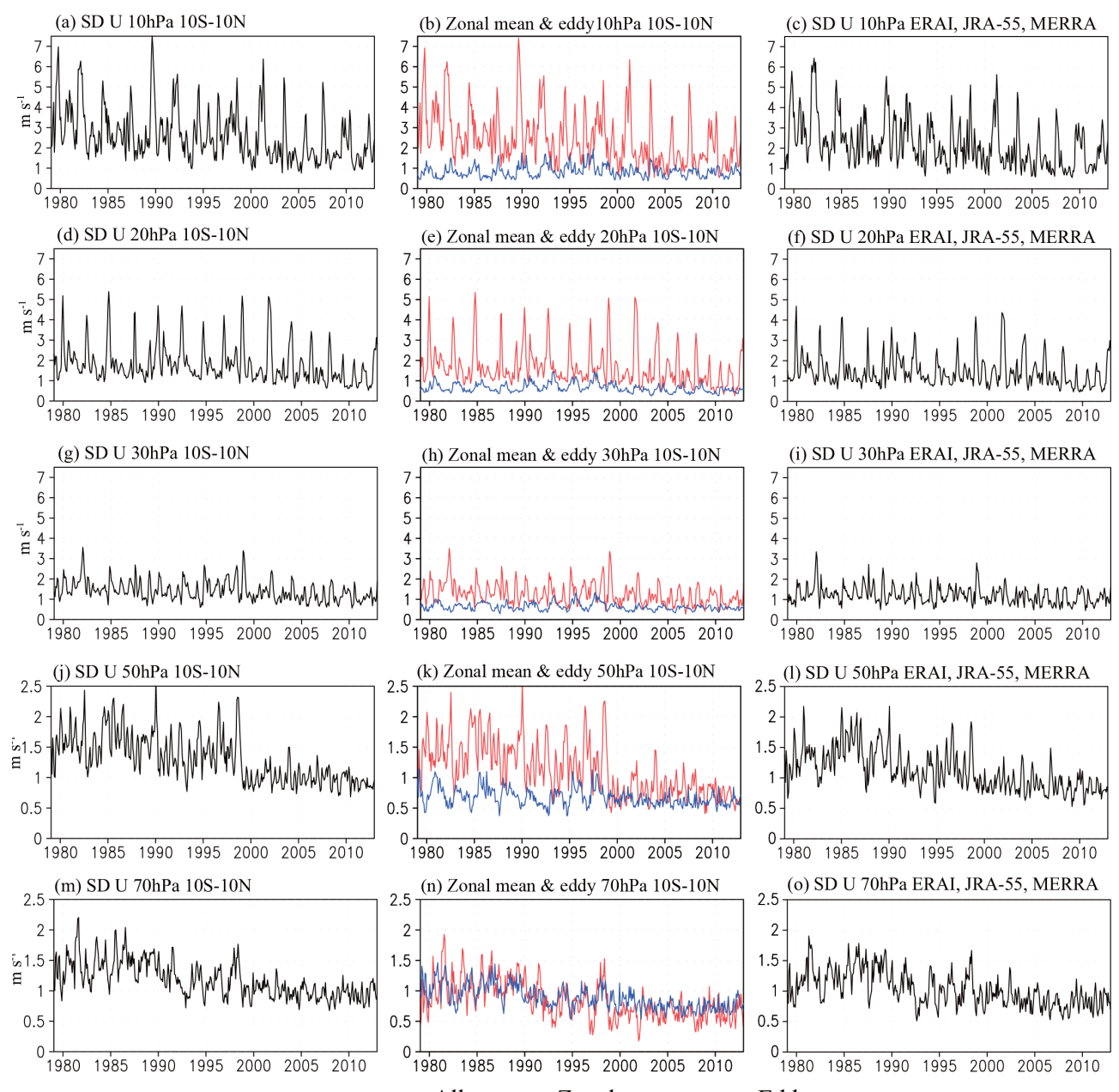

Figure 13. Time variations of zonal mean standard deviation of (black) all, (red) zonal mean, and (blue) eddy components among (left and middle) four reanalyses (ERA-I, JRA-25, JRA-55, and MERRA), and among (right) three reanalyses (ERA-I, JRA-55, and MERRA) from 1979 to 2012 at $10,20,30,50$, and $70 \mathrm{hPa}$ in $10^{\circ} \mathrm{S}-10^{\circ} \mathrm{N}$.

the use of multivariate background error covariance matrix at analysis step even though the coupling of temperature and wind may be somewhat weak as the Coriolis parameter is small near the Equator. Thermal wind shears will be very sensitive to small errors in observed temperatures. After 2000 the amount of available satellite data increased greatly (e.g., Kobayashi et al., 2015), and the contributions of satellite radiance data to better representation of the tropical winds presumably also increased. However, it is hard to quantify the relative roles of global satellites and in situ radiosonde observations in reducing the zonal wind SD among reanalyses.

Finally, Fig. $17 \mathrm{a}-\mathrm{d}$ are the horizontal maps at $50-70 \mathrm{hPa}$ SD among the three most modern reanalyses (ERA-I, JRA55, and MERRA) illustrated for 2001-2011, when the SD is smallest (Fig. 12). Here, we also calculated SD between ERA-I and JRA-55, ERA-I and MERRA, and JRA-55 and MERRA separately. The SD becomes larger when JRA-55 data are included, and the SD between ERA-I and MERRA is smallest. However, in any case, the geographical patterns of the SD are always similar, independent of the reanalysis or period selected (see Figs. 4, 12, and 17). These results indicate the importance of zonal wind observations by local radiosondes for better representation of the tropical zonal wind in the lower stratosphere in reanalysis data sets. Just for reference, the same figure, but between MERRA and MERRA-2, is shown in Fig. 17e. The geographical pattern is also similar, even though the MERRA-2 assimilation was notable in using a dynamical model that simulated a spontaneous QBO.

\section{Summary and concluding remarks}

This paper reports on a project to compare the representation of the monthly-mean zonal wind in the equatorial stratosphere among major global atmospheric reanalyses data sets. We mainly confined our analysis to $20^{\circ} \mathrm{N}-20^{\circ} \mathrm{S}$ and 10 
(a) SD temperature 10S-10N ERA-I, JRA-25, JRA-55, MERRA

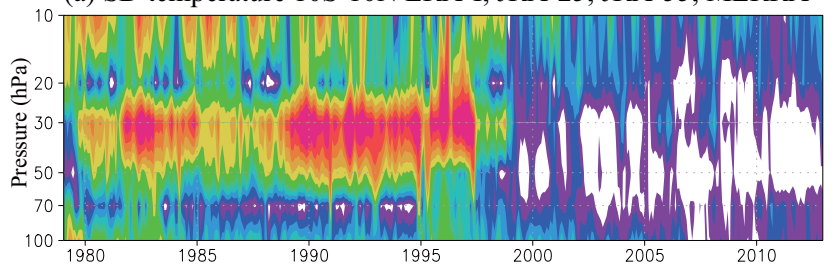

(b) SD temperature 10S-10N ERA-I, JRA-55, MERRA

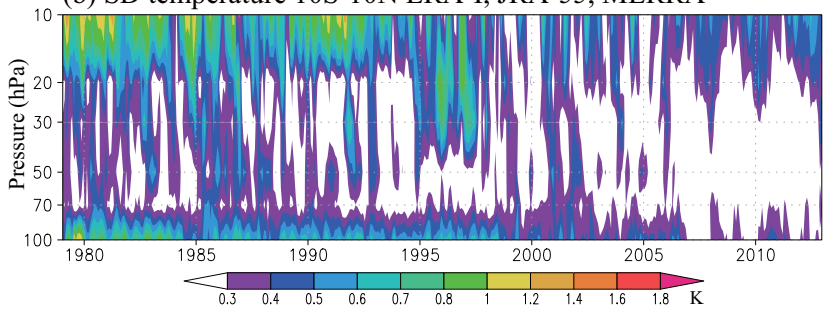

Figure 14. Time-height cross sections of zonal mean standard deviation of temperature among (a) four reanalyses (ERA-I, JRA-25, JRA-55, and MERRA) and (b) three reanalysis (ERA-I, JRA-55, and MERRA) at $10^{\circ} \mathrm{S}-10^{\circ} \mathrm{N}$ from 1979 to 2012 . The color intervals are $0.1 \mathrm{~K}$ for values less than 0.8 and $0.2 \mathrm{~K}$ for values more than $0.8 \mathrm{~K}$.

$70 \mathrm{hPa}$ and to data starting in 1979 (i.e., after the availability of operational satellite temperature soundings). We compared the zonal wind in the reanalyses with the FUB data set for equatorial monthly-mean winds, which, for this period, were based on balloon observations in Singapore. We also compared reanalysis values with balloon observations at many other low-latitude stations included in the IGRA.

All nine reanalyses data sets we examined display monthly-mean zonal wind values in Singapore that are reasonably close to the directly observed values at all levels between 70 and $10 \mathrm{hPa}$ (Fig. 2). However, the NCEP-1 and NCEP-2 analyses have significantly larger differences with the Singapore observations than the other reanalyses. Notably, NCEP-1 and NCEP-2 display considerably weaker (as much as $10 \mathrm{~m} \mathrm{~s}^{-1}$ ) easterly QBO extremes than is apparent in the balloon observations, particularly during the 1980s. MERRA-2 also stands out as an outlier in displaying large differences from FUB at $10 \mathrm{hPa}$ in the 1980s and in November-December 1993. The NCEP-CFSR uses the ERA-40 winds in the tropical stratosphere from July 1981 to December 1998, and the differences between NCEP-CFSR and ERA-40 during this period are nearly 0 . Further analysis and discussion here was largely restricted to the other five reanalyses (ERA-40, ERA-I, JRA-25, JRA-55, and MERRA).

We characterized the degree of disagreement among the reanalyses by the SD of the monthly-mean zonal wind values in the five data sets. This measure is a function of height, latitude, longitude, and time. At each height the SD displays a prominent equatorial maximum, indicating the particularly challenging nature of the reanalysis problem in the low-latitude stratosphere where in situ observations are rela- (a) $10 \mathrm{hPa}$ Radiosonde $10^{\circ} \mathrm{S}-10^{\circ} \mathrm{N}$

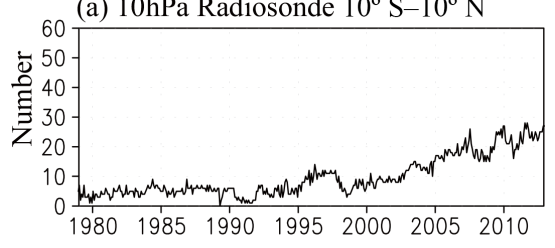

(b) $20 \mathrm{hPa}$ Radiosonde $10^{\circ} \mathrm{S}-10^{\circ} \mathrm{N}$

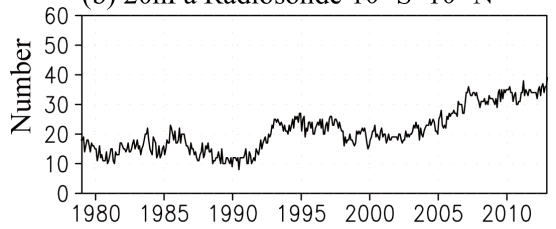

(c) $30 \mathrm{hPa}$ Radiosonde $10^{\circ} \mathrm{S}-10^{\circ} \mathrm{N}$

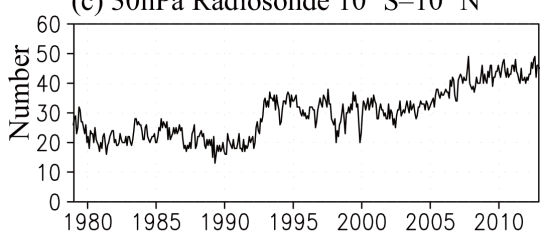

(d) $50 \mathrm{hPa}$ Radiosonde $10^{\circ} \mathrm{S}-10^{\circ} \mathrm{N}$
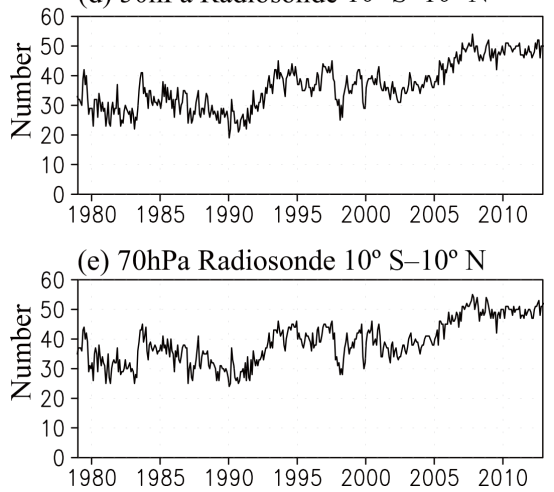

Figure 15. Time variation in number of radiosonde observations at $10^{\circ} \mathrm{S}-10^{\circ} \mathrm{N}$ at (a) 10 , (b) 20 , (c) 30 , (d) 50 , and (e) $70 \mathrm{hPa}$ from 1979 to 2012 .

tively sparse and the Coriolis parameter is small. The SD in the tropical stratosphere also depends significantly on both longitude and height (Fig. 4). At $50-70 \mathrm{hPa}$, a large SD is seen for the Indian Ocean, to the east of the maritime continent, the central Pacific, and the Atlantic, showing clear zonally non-uniform structures. At $10-30 \mathrm{hPa}$, however, the SD becomes more zonally uniform.

At $50-70 \mathrm{hPa}$, the distributions of the SD are closely related with those of in situ radiosonde observations (Fig. 5e, f). The region of largest SD extends over wide zonal range in the central Pacific, where few observations are available. In the vicinity of individual radiosonde stations the $\mathrm{SD}$ at $70 \mathrm{hPa}$ generally reduces in periods when observations are available relative to periods with no observations (Fig. 6).

At each level there is a tendency for agreement to be best near the longitude of Singapore (a result that holds in all QBO phases), suggesting that the high-quality Singapore balloon observations act as a strong constraint on all the reanal- 

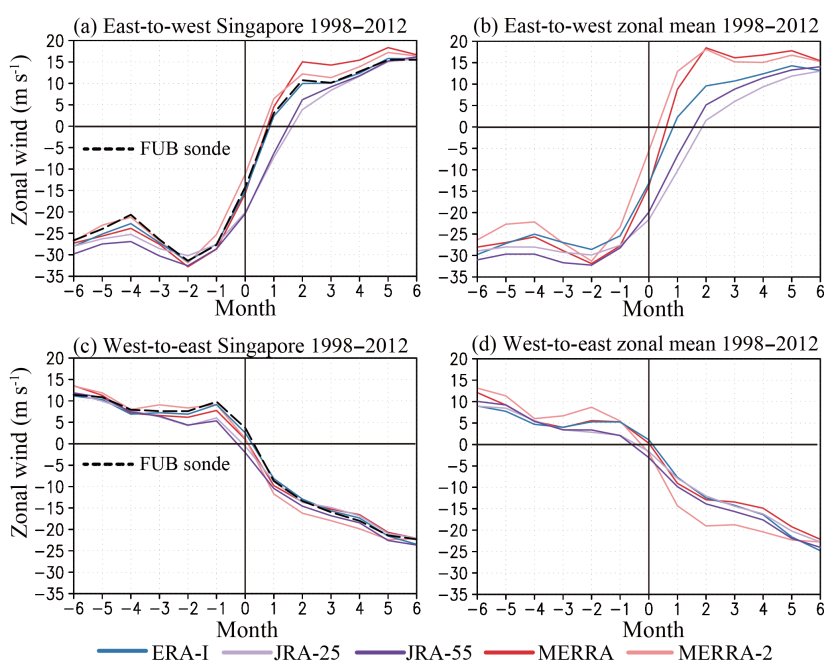

Figure 16. Same as Fig. 9a-d but during 1998 to 2012, excluding ERA-40 and including MERRA-2.

yses. At 10 and $20 \mathrm{hPa}$, the zonal mean SD has a clear dependence on the phase of the QBO (Fig. 8). Specifically the SD generally jumps to $5-10 \mathrm{~m} \mathrm{~s}^{-1}$ for a few months around the transition from easterly to westerly. At $30 \mathrm{hPa}$, the difference is smaller (almost always less than $5 \mathrm{~m} \mathrm{~s}^{-1}$ ) but it still shows the same QBO dependence. The main discrepancy with FUB observations at these heights is a tendency for the zonal wind accelerations to be delayed in the all reanalyses, except MERRA, around the easterly-to-westerly transition (Fig. 9).

At $10 \mathrm{hPa}$, all the reanalyses show that the eddy component (i.e., the deviation of the zonal wind values from the zonal mean) in the monthly-mean zonal wind near the Equator is dominated by zonal wavenumber 1 and 2 quasistationary planetary waves propagating from midlatitudes (Fig. 10). Consistent with this, the eddy component of the zonal wind near the Equator is small in months with zonal mean easterlies and generally much larger in months with zonal mean westerlies. While the different reanalyses agree in broad terms about the structure of the eddy components in the middle stratosphere, there generally remains considerable disagreement among the reanalyses in the details of the quasi-stationary waves near the Equator. At $50-70 \mathrm{hPa}$ the SD distributions are not strongly affected by the phase of the QBO. The eddy features at these heights, rather than being planetary waves from midlatitudes, might be related to stratospheric penetration of the Walker circulation (Fig. 7).

Our measures reflecting the reliability of the reanalyses show systematic improvement over the 1979-2012 period considered. Specifically, the agreement of the reanalysis results with the Singapore data improves significantly with time, with average deviations from the observation reduced by almost half from that in the early 1980 s to the 2010 s (Fig. 2f). At 50-70 $\mathrm{hPa}$, the magnitude of the SD among the
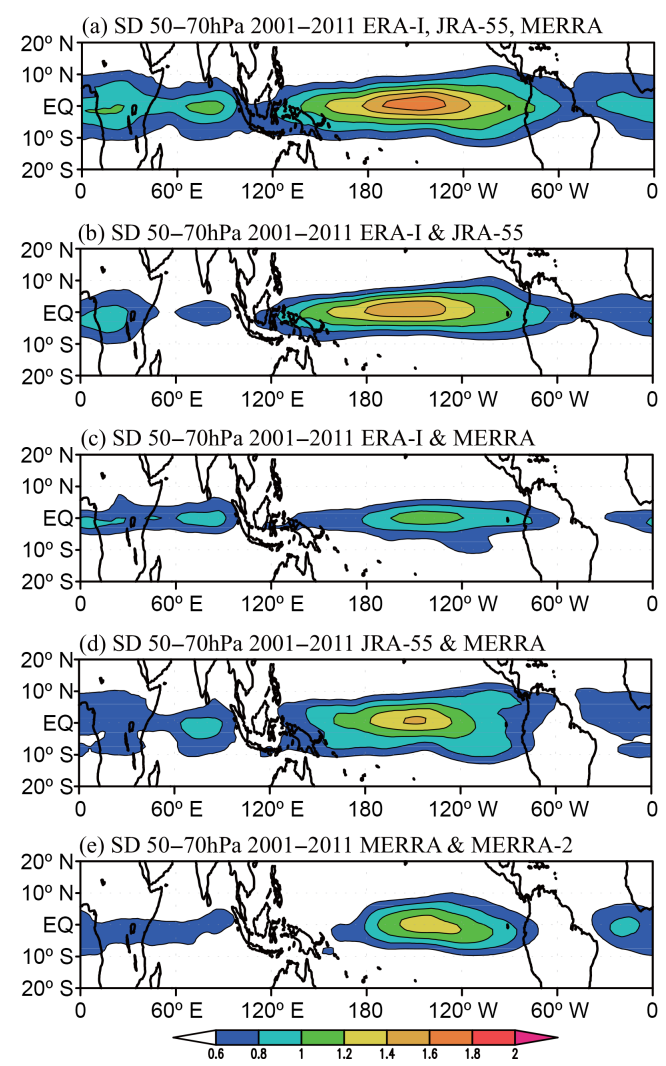

Figure 17. Same as Fig. 12c but for the standard deviation among (a) three reanalysis (ERA-I, JRA-55, and MERRA), (b) between ERA-I and JRA-55, (c) between ERA-I and MERRA, (d) between JRA-55 and MERRA, and (e) between MERRA and MERRA-2.

reanalyses declines significantly over the period of record (Fig. 13), although the geographical pattern of differences (as measured by the SD of the five reanalysis values) is nearly constant (Fig. 12).

For any individual reanalysis, the same atmospheric dynamical model and the same assimilation procedures are used throughout the whole period; thus any improvement seen in the quality with time must be related to changes in the observational data used. The number of available in situ radiosonde observations increase with time at all levels (Fig. 15). In addition, satellite data streams vary throughout this period. The end of 1978 saw the introduction of the SSU, which was flown on NOAA operational satellites for the next 2 decades (NOAA8 though NOAA14). We expect an important upgrade may have occurred in May 1998 when the temperature sounders on NOAA operational satellites were upgraded from the SSU to the AMSU. The satellite streams continued to show changes with the introduction of more AMSU instruments flying on other satellites. Additionally, new sources of radiance data also appeared, such as the Atmospheric Infrared Sounder (AIRS) flown on the NASA Aqua satellite in 2002. 
Doing assimilation experiments removing certain data sets from the analysis and exploring the impact of particular data sets is one possible way to investigate the data included. The effects of satellite data sets might be investigated by comparison between JRA-55 and JRA-55c (which excludes all satellite data as input). Kobayashi et al. (2014) compare the JRA-55 and JRA-55C reanalyses and indicate that the tropical zonal wind difference between the JRA-55 and JRA-55C is large in the upper stratosphere compared to that in the lower stratosphere, and the amplitude in JRA-55C is smaller than that of the JRA-55. More detail comparisons along these lines are reserved for future work.

The magnitude of the SD in the horizontal winds throughout the tropics would be worth highlighting for trajectory studies given that there is some inclination to assume that the key the inter-reanalysis differences for chemical transport are in the vertical velocities. Abalos et al. (2015) have recently compared the stratospheric Brewer-Dobson circulation among MERRA, ERA-I, and JRA55, while Miyazaki et al. (2016) did a somewhat similar study with six different reanalyses. Abalos et al. (2015) find quite large ( $\sim 40 \%)$ differences among the reanalyses in the overall strength of the BD circulation and a large spread among the estimates of the fraction of variance in mean vertical motion explained by the QBO. Coy et al. (2016) found that MERRA-2, which internally generates the QBO, has reduced the zonal wind analysis increments compared to MERRA, so that the QBO mean meridional circulation can be expected to be more physically forced and more physically consistent.

The difference among reanalyses using twice daily data should be much larger than our SD based on monthly-mean data (cf. Baker et al., 2014). Podglajen et al. (2014) compare reanalyses winds with independent in situ observations performed along long-duration balloon flights. They report that ERA-I and MERRA represent similar disturbances associated with equatorial waves, but reanalyses depart from the balloon observations. As the present study focus on monthly-mean field, our analyses ignore variability with shorter timescales.

Our study confirms that even with relatively few balloon stations, the high-accuracy and high-resolution wind measurements by in situ radiosondes have provided important constraints to reanalyses of circulation in the tropical stratosphere. Our analysis also shows that changes in both satellite and balloon data availability over the years have significantly affected the reanalysis of zonal wind data for the equatorial stratosphere. This conclusion has a negative aspect as it suggests that using reanalysis products (even restricting the data to after 1978) does not enable a researcher to avoid all significant artificial trends. On the positive side, it seems that the changes in available data have led to continually improving reanalysis representation of the tropical stratosphere.

\section{Data availability}

The monthly mean zonal wind values of operational balloonborne radiosonde observations compiled by the Free University of Berlin are available at http://www.geo.fu-berlin.de/en/ met/ag/strat/produkte/qbo/ (Freie Universität Berlin, 2016).

The monthly-mean values of the zonal wind at many radiosonde stations provided in the Integrated Global Radiosonde Archive are available at https://www.ncdc.noaa.gov/data-access/weather-balloon/ integrated-global-radiosonde-archive (NOAA, 2016).

Acknowledgements. We thank M. A. Geller, A. Hertzog, and three anonymous reviewers for constructive comments on the original manuscript. We also express our gratitude to S-RIP members for providing useful information about the reanalyses data. This research was supported by Grant-in-Aid for Scientific Research B (26287117) and Joint international Research (15KK0178) from the Japan Society for the Promotion of Science, and by the Environment Research and Technology Development Fund (2-1503) of the Ministry of the Environment, Japan. This research was also supported by the Japan Agency for Marine-Earth Science and Technology (JAMSTEC) through its sponsorship of research at the International Pacific Research Center and by NOAA through grant no. NA11NMF4320128. The GFD-DENNOU Library and GrADS were used to draw the figures.

Edited by: P. Haynes

\section{References}

Abalos, M., Legras, B., Ploeger, F. and Randel, W. J.: Evaluating the advective Brewer-Dobson circulation in three reanalyses for the period 1979-2012, J. Geophys. Res.-Atmos., 120, 7534-7554, doi:10.1002/2015JD023182, 2015.

Anstey, J. A., Scinocca, J. F., and Keller, M.: Simulating the QBO in an atmospheric general circulation model: sensitivity to resolved and parameterized forcing, J. Atmos. Sci., 73, 1649-1665, 2016.

Baldwin, M. P. and Gray, L. J.: Tropical stratospheric zonal winds in ECMWF ERA-40 reanalysis, rocketsonde data, and rawinsonde data, Geophys. Res. Lett., 32, L09806, doi:10.1029/2004GL022328, 2005.

Baldwin, M. P., Gray, L. J., Dunkerton, T. J., Hamilton, K., Haynes, P. H., Randel, W. J., Holton, J. R., Alexander, M. J., Hirota, I., Horinouchi, T., Jones, D. B. A., Kinnersley, J. S., Marquardt, C., Sato, K., and Takahashi, M.: The quasi-biennial oscillation, Rev. Geophys., 39, 179-229, 2001.

Baker, W. E., Atlas, R., Cardinali, C., Clement, A., Emmitt, G., Gentry, B. M., Hardesty, R. M., Källén, E., Kavaya, M. J., Langland, R., Ma, Z.,Masutani, M., McCarty, W., Pierce, R. B., Pu, Z., Riishojgaard, L. P., Ryan, J., Tucker, S., Weissmann, M., and Yoe, J. G.: LIDAR-MEASURED WIND PROFILES The Missing Link in the Global Observing System, B. Am. Meteorol. Soc., 95, 543-564, doi:10.1175/BAMS-D-12-00164.1, 2014.

Boer, G. and Hamilton, K.: QBO influence on extratropical predictive skill, Clim. Dynam., 31, 987-1000, doi:10.1007/s00382008-0379-5, 2008. 
Coy, L. and Swinbank, R.: Characteristics of stratospheric winds and temperatures produced by data assimilation, J. Geophys. Res., 102, 25763-25781, 1997.

Coy, L., Wargan, K., Molod, A., McCarty, W., and Pawson, S: Structure and Dynamics of the Quasi-Biennial Oscillation in MERRA2, J. Climate, doi:10.1175/JCLI-D-15-0809.1, online first, 2016.

Dee, D. P., Uppala, S. M., Simmons, A. J., Berrisford, P., Poli, P., Kobayashi, S., Andrae, U., Balmaseda, M. A., Balsamo, G., Bauer, P., Bechtold, P., Beljaars, A. C. M., van de Berg, L., Bidlot, J., Bormann, N., Delsol, C., Dragani, R., Fuentes, M., Geer, A. J., Haimberger, L., Healy, S. B., Hersbach, H., Hólm, E. V., Isaksen, L., Kållberg, P., Köhler, M., Matricardi, M., McNally, A. P., Monge-Sanz, B. M., Morcrette, J.-J., Park, B.-K., Peubey, C., de Rosnay, P., Tavolato, C., Thépaut, J.-N., and Vitart, F.: The ERA-Interim reanalysis: configuration and performance of the data assimilation system, Q. J. Roy. Meteor. Soc., 137, 553-597, 2011.

Durre, I., Russell S. V., and David B. W.: Overview of the Integrated Global Radiosonde Archive, J. Climate, 19, 53-68, 2006.

Errera, Q., Fujiwara, M., Long, C., and Jackson, D.: Report on the 10th SPARC data assimilation workshop and the 2014 SPARC Reanalysis Intercomparison Project (S-RIP) workshop, SPARC Newsletter, 44, 31-37, 2015.

Freie Universität Berlin: The Quasi-Biennial-Oscillation (QBO) Data Serie, available at: http://www.geo.fu-berlin.de/en/met/ag/ strat/produkte/qbo/, last access: 1 June 2016.

Fujiwara, M. and Jackson, D.: SPARC Reanalysis Intercomparison Project (S-RIP) Planning Meeting, 29 April-1 May 2013, Exeter, UK: SPARC Newsletter, 41, 52-55, 2013.

Fujiwara, M., Hibino, T., Mehta, S. K., Gray, L., Mitchell, D., and Anstey, J.: Global temperature response to the major volcanic eruptions in multiple reanalysis data sets, Atmos. Chem. Phys., 15, 13507-13518, doi:10.5194/acp-15-13507-2015, 2015.

Hamilton, K.: Mean wind evolution through the quasi-biennial cycle of the tropical lower stratosphere, J. Atmos. Sci., 41, 21132125, 1984.

Hamilton, K. and Yuan, L.: Experiments on tropical stratospheric mean wind variations in a spectral general circulation model, J. Atmos. Sci., 49, 2464-2483, 1992.

Hamilton, K., Hertzog, A., and Vial, F.: and Stenchikov, G., Longitudinal variation of the stratospheric quasi-biennial oscillation, J. Atmos. Sci., 61, 383-402, 2004.

Huesmann, A. S. and Hitchman, M. H.: The stratospheric quasibiennial oscillation in the NCEP reanalyses: Climatological structures, J. Geophys. Res., 106, 11859-11874, 2001.

Huesmann, A. S. and Hitchman, M. H.: The 1978 shift in the NCEP reanalysis stratospheric quasi-biennial oscillation, Geophys. Res. Lett., 30, 1048, doi:10.1029/2002GL016323, 2003.

Iida, C., Hirooka, T., and Eguchi, N.: Circulation changes in the stratosphere and mesosphere during the stratospheric sudden warming event in January 2009, J. Geophys. Res.-Atmos., 119, 7104-7115, 2014.

Kalnay, E.: Atmospheric Modeling, Data Assimilation and Predictability, Cambridge University Press, 341 pp., 2003.

Kalnay, E., Kanamitsu, M., Kistler, R., Collins, W., Deaven, D., Gandin, L., Iredell, M., Saha, S., White, G., Woollen, J., Zhu, Y., Chelliah, M., Ebisuzaki, W., Higgins, W., Janowiak, J., Mo, K. C., Ropelewski, C., Wang, J., Leetmaa, A., Reynolds, R.,
Jenne, R., and Joseph, D.: The NCEP/NCAR 40-year reanalyses project, B. Am. Meteorol. Soc., 77, 437-471, 1996.

Kanamitsu, M., Ebisuzaki, W., Woollen, J., Yang, S.-K., Hnilo, J. J., Fiorino, M., and Potter, G. L.: NCEP-DOE AMIP-II Reanalysis (R-2), B. Am. Meteorol. Soc., 83, 1631-1643, 2002.

Kawatani, Y. and Hamilton, K.: Weakened stratospheric quasibiennial oscillation driven by increased tropical mean upwelling, Nature, 497, 478-481, 2013.

Kawatani, Y., Sato, K., Dunkerton, T. J., Watanabe, S., Miyahara, S., and Takahashi, M.: The roles of equatorial trapped waves and internal inertia-gravity waves in driving the quasi-biennial oscillation. Part I: Zonal mean wave forcing, J. Atmos. Sci., 67, 963-980, 2010.

Kawatani, Y., Hamilton, K., and Watanabe, S.: The quasi-biennial oscillation in a double $\mathrm{CO}_{2}$ climate, J. Atmos. Sci., 68, 265-283, 2011.

Kim, Y.-H. and Chun, H.-Y.: Momentum forcing of the quasibiennial oscillation by equatorial waves in recent reanalyses, Atmos. Chem. Phys., 15, 6577-6587, doi:10.5194/acp-15-65772015, 2015.

Kobayashi, C., Endo, H., Ota, Y., Kobayashi, S., Onoda, H., Harada, Y., Onogi, K., and Kamahori, H.: Preliminary results of the JRA-55C, an atmospheric reanalysis assimilating conventional observations only. Sci. Online Lett. on the Atmos., 10, 78-82, doi:10.2151/sola.2014-016, 2014

Kobayashi, S., Ota, Y., Harada, Y., Ebita, A., Moriya, M., Hirokatsu, O., Onogi, K., Kamahori, H., Kobayashi, C., Endo, H., Miyaoka, K., and Takahashi, K.: The JRA-55 Reanalysis: general specifications and basic characteristics, J. Meteorol. Soc. Jpn., 93, 5-48, 2015.

Miyazaki, K., Iwasaki, T., Kawatani, Y., Kobayashi, C., Sugawara, S., and Hegglin, M. I.: Inter-comparison of stratospheric meanmeridional circulation and eddy mixing among six reanalysis data sets, Atmos. Chem. Phys., 16, 6131-6152, doi:10.5194/acp16-6131-2016, 2016.

Molod, A., Takacs, L., Suarez, M., and Bacmeister, J.: Development of the GEOS-5 atmospheric general circulation model: evolution from MERRA to MERRA2, Geosci. Model Dev., 8, 1339-1356, doi:10.5194/gmd-8-1339-2015, 2015.

Naujokat, B.: An update of the observed quasi-biennial oscillation of the stratospheric zonal wind over the tropics, J. Atmos. Sci., 43, 1873-1877, 1986.

NOAA: Integrated Global Radiosonde Archive (IGRA), available at: https://www.ncdc.noaa.gov/data-access/weather-balloon/ integrated-global-radiosonde-archive, last access: 1 June 2016.

Onogi, K., J. Tsutsui, J., Koide, H., Sakamoto, M., Kobayashi, S., Hatsushika, H., Matsumoto, T., Yamazaki, N., Kamahori, H., Takahashi, K., Kadokura, S., Wada, K., Kato, K., Oyama, R., Ose, T., Mannoji, N., and Taira, R.: The JRA-25 reanalysis, J. Meteorol. Soc. Jpn., 85, 369-432, 2007.

Orr, A., Bechtold, P., Scinocca, J., Ern, M., and Janiskova, M.: Improved middle atmosphere climate and forecasts in the ECMWF model through a nonorographic gravity wave drag parameterization, J. Climate, 23, 5905-5926, 2010.

Pascoe, C. L., Gray, L. J., Crooks, S. A., Juckes, M. N., and Baldwin, M. P.: The quasi-biennial oscillation: Analysis using ERA-40 data, J. Geophys. Res., 110, D08105, doi:10.1029/2004JD004941, 2005. 
Pawson, S. and Fiorino, M.: A comparison of reanalyses in the tropical stratosphere, Part 2: the quasi-biennial oscillation, Clim. Dynam., 14, 645-658, 1998.

Pawson, S. and Fiorino, M.: A comparison of reanalyses in the tropical stratosphere, Part 3: Inclusion of the pre-satellite data era, Clim. Dynam., 15, 241-250, 1999.

Podglajen, A., Hertzog, A., Plougonven, R., and Žagar, N.: Assessment of the accuracy of (re)analyses in the equatorial lower stratosphere, J. Geophys. Res., 119, 11166-11188, doi:10.1002/2014JD021849, 2014.

Rienecker, M. M., Suarez, M. J., Gelaro, R., Todling, R., Bacmeister, J., Liu, E., Bosilovich, M. G., Schubert, S. D., Takacs, L., Kim, G-K., Bloom, S., Chen, J., Collins, D., Conaty, A., da Silva, A., Gu, W., Joiner, J., Koster, R. D., Lucchesi, R., Molod, A., Owens, T., Pawson, S., Pegion, P., Redder, C. R., Reichle, R., Robertson, F. R., Ruddick, A. G., Sienkiewicz, M., and Woollen, J.: MERRA: NASA's Modern-Era Retrospective Analysis for Research and Applications, J. Climate, 24, 3624-3648, 2011.

Randel, W. J., Wu, F., Swinbank, R., Nash, J., and O'Neill, A.: Global QBO circulation derived from UKMO stratospheric analyses, J. Atmos. Sci., 56, 457-474, 1999.

Randel, W. J., Udelhofen, F., Fleming, E., Geller, M., Gelman, M., Hamilton, K., Karoly, D., Ortland, D., Pawson, S., Swinbank, R., Wu, F., Baldwin, M., Chanin, M., Keckhut, P., Labitzke, K., Remsberg, E., Simmons, A., and Wu, D.: The SPARC intercomparison of middle-atmosphere climatologies, J. Climate, 17, 986-1003, 2004.

Reed, R. J.: Evidence of geostrophic motion in the equatorial stratosphere, Q. J. R. Meteor. Soc., 88, 324-327, 1962.

Saha, S., Nadiga, S., Thiaw, C., Wang, J., Wang, W., Zhang, Q., van den Dool, H. M., Pan, H.-L., Moorthi, S., Behringer, D., Stokes, D., Peña, M., Lord, S., White, G., Ebisuzaki, W., Peng, P., and Xie, P.: The NCEP climate forecast system, J. Climate, 19, 3483$3517,2006$.
Saha, S., Moorthi, S., Pan, H.-L., Wu, X., Wang, J., Nadiga, S., Tripp, P., Kistler, R., Woollen, J., Behringer, D., Liu, H., Stokes, D., Grumbine, R., Gayno, G., Wang, J., Hou, Y.-T., Chuang, H.Y., Juang, H.-M. H., Sela, J., Iredell, M., Treadon, R., Kleist, D., Delst, P. V., Keyser, D., Derber, J., Ek, M., Meng, J., Wei, H, Yang, R., Lord, S., Dool, H. V. D., Kumar, A., Wang, W., Long, C., Chelliah, M., Xue, Y., Huang, B., Schemm, J.-K., Ebisuzaki, W., Lin, R., Xie, P., Chen, M., Zhou, S., Higgins, W., Zou, C.-Z., Liu, Q., Chen, Y., Han, Y., Cucurull, L., Reynolds, R. W., Rutledge, G., and Goldberg, M.: The NCEP Climate Forecast System Reanalysis, B. Am. Meteorol. Soc., 91, 1015-1057, 2010.

Trenberth, K. E.: Global analyses from ECMWF and atlas of 1000 to $10 \mathrm{Mb}$ circulation statistics, NCAR Technical Note NCAR/TN-373+STR, doi:10.5065/D6WM1BCN, 1992.

Uppala S. M., Kallberg, P. W., Simmons, A. J., Andrae, U., Bechtold, V. D., Fiorino, M., Gibson, J. K., Haseler, J., Hernandez, A., Kelly, G. A., Li, X., Onogi, K., Saarinen, S., Sokka, N., Allan, R. P., Andersson, E., Arpe, K., Balmaseda, M. A., Beljaars, A. C. M., van de Berg, L., Bidlot, J., Bormann, N., Caires, S., Chevallier, F., Dethof, A., Dragosavac, M., Fisher, M., Fuentes, M., Hagemann, S., Holm, E., Hoskins, B. J., Isaksen, L., Janssen, P. A. E. M., Jenne, R., McNally, A. P., Mahfouf, J. F., Morcrette, J. J., Rayner, N. A., Saunders, R. W., Simon, P., Sterl, A., Trenberth, K. E., Untch, A., Vasiljevic, D., Viterbo, P., and Woollen, J.: The ERA-40 re-analysis, Q. J. Roy. Meteor. Soc., 131, 29613012, 2005.

Wallace, J. M.: General circulation of the tropical lower stratosphere, Rev. Geophys., 11, 191-222, 1973.

Yoo, C. and Son, S.-W.: Modulation of the boreal wintertime Madden-Julian oscillation by the stratospheric quasibiennial oscillation, Geophys. Res. Lett., 43, 1392-1398, doi:10.1002/2016GL067762, 2016. 